University of Louisville

ThinkIR: The University of Louisville's Institutional Repository

$12-2010$

\title{
Adriamycin nephrotoxicity is reduced by metallothionein over- expression and kidney gene expression is modified by diabetes in the OVE26 diabetic model.
}

Lu Yang

University of Louisville

Follow this and additional works at: https://ir.library.louisville.edu/etd

\section{Recommended Citation}

Yang, Lu, "Adriamycin nephrotoxicity is reduced by metallothionein over-expression and kidney gene expression is modified by diabetes in the OVE26 diabetic model." (2010). Electronic Theses and Dissertations. Paper 1618.

https://doi.org/10.18297/etd/1618

This Doctoral Dissertation is brought to you for free and open access by ThinkIR: The University of Louisville's Institutional Repository. It has been accepted for inclusion in Electronic Theses and Dissertations by an authorized administrator of ThinkIR: The University of Louisville's Institutional Repository. This title appears here courtesy of the author, who has retained all other copyrights. For more information, please contact thinkir@louisville.edu. 


\title{
ADRIAMYCIN NEPHROTOXICITY IS REDUCED BY \\ METALLOTHIONEIN OVER-EXPRESSION AND KIDNEY GENE EXPRESSION IS \\ MODIFIED BY DIABETES IN THE OVE26 DIABETIC MODEL
}

By

\section{Lu Yang}

B.S., University of Science \& Technology of China, 2004

M.S, University of Louisville, 2007

\begin{abstract}
A Dissertation
Submitted to the Faculty of the

Graduate School of the University of Louisville

In Partial Fulfillment of the Requirements

For the Degree of
\end{abstract}

Doctor of Philosophy

Department Pharmacology and Toxicology

University of Louisville, School of Medicine

Louisville, Kentucky

December 2010 



\section{ADRIAMYCIN NEPHROTOXICITY IS REDUCED BY METALLOTHIONEIN OVER-EXPRESSION AND KIDNEY GENE EXPRESSION IS MODIFIED BY DIABETES IN THE OVE26 DIABETIC MODEL}

By

Lu Yang

B.S., University of Science \& Technology of China, 2004

M.S., University of Louisville, 2007

A Dissertation Approved on

November 16,2010

by the following Dissertation Committee:

Paul N. Epstein Ph.D.

William M. Pierce, Jr., Ph.D.

John W. Eaton, Ph.D.

Jon B. Klein, M.D., Ph.D.

Richard E. Goldstein, M.D., Ph.D. 


\section{ACKNOWLEDGMENTS}

This dissertation would not have been a real fulfillment without the backing and cooperation from various individuals through various means.

I am heartily thankful to my supervisor, Dr. Paul N. Epstein, whose encouragement, guidance and support from the initial to the final level enabled me to develop an understanding of the subject. It is Dr. Epstein who always served so well as the model for my own academic and scientific career. I am, indeed, quite fortunate to have the honor of his mentorship.

I would also like to thank every single one of committee members: Drs. John W. Eaton, Jon B. Klein, William M. Pierce and Richard E. Goldstein, for their most helpful directions and suggestions.

Most importantly, none of this would have been possible without the unconditional love and patience of my family. My husband, Haiyang Wei, to whom this dissertation is dedicated, has been a constant source of love, concern, support and strength all these years. Lastly, I offer my regards and blessings to all of my co-workers in the lab, my friends and my parents, who supported me in any respect during the completion of the project. 


\begin{abstract}
ADRIAMYCIN NEPHROTOXICITY IS REDUCED BY METALLOTHIONEIN OVER-EXPRESSION AND KIDNEY GENE EXPRESSION IS MODIFIED BY DIABETES IN THE OVE26 DIABETIC MODEL
\end{abstract}

Lu Yang

December 3, 2010

This thesis is divided into two parts below.

\title{
Part I
}

Adriamycin (ADR) can produce nephrotoxicity in rodents. The underlying mechanism may relate to ADR induced oxidative stress. In this study, we used transgenic mice (NMT3), which over-expressed the antioxidant protein metallothionein (MT) in podocytes, to study MT's protective potential on ADR nephrotoxicity. Urine and kidney samples were collected from control and transgenic mice at multiple time points after ADR injection, whose results showed that MT transgene alleviated ADR damage by reducing albuminuria, decreasing podocyte loss and protecting podocyte ultra-structure.

Part II

OVE26 mice are a good model of severe diabetic nephropathy (DN). We examined progressive changes in renal gene and protein expression in OVE26 and control mice. Inflammatory genes were most affected by diabetes, especially at oldest ages tested, 
which correlated with increasingly severe albuminuria. Vitamin D metabolism was also changed by DN. 


\section{TABLE OF CONTENTS}

PAGE

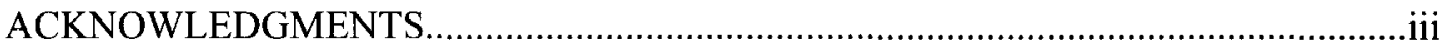

ABSTRACT

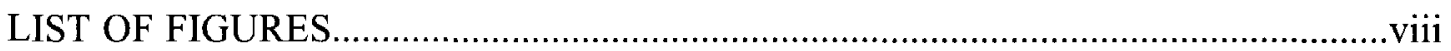
CHAPTER

I. METALLOTHIONEIN OVER-EXPRESSION IN PODOCYTES REDUCES ADRIAMYCIN NEPHROTOXICITY

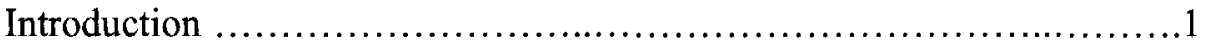

Methods and materials.............................................

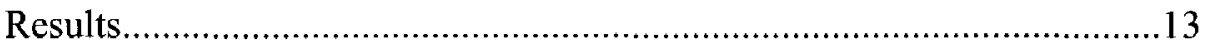

Discussion.............................................................

II. GENE EXPRESSION DURING PROGRESSION OF DIABETIC NEPHROPATHY

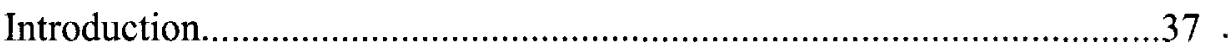

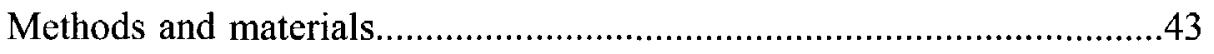

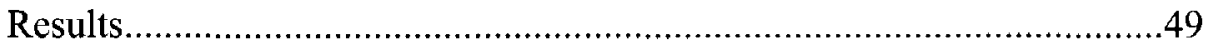

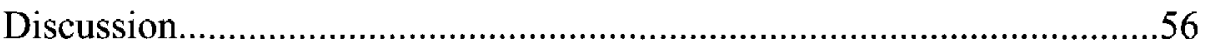




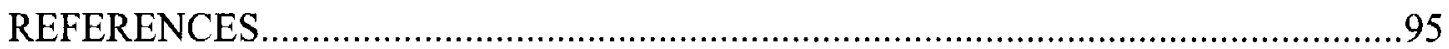

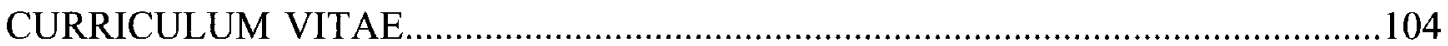




\section{LIST OF FIGURES}

FIGURE

PAGE

Chapter I

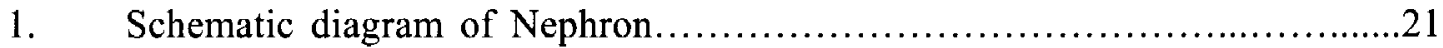

2. ADR increases urine albumin (UAE) and total protein excretion in FVB mice

3. Expression of MT in Nmt transgenic and FVB control mice .25

4. F-actin filaments are resistant to $\mathrm{H}_{2} \mathrm{O}_{2}$ in $\mathrm{Nmt}$ podocytes 27

5. MT over-expression reduces ADR-induced albuminuria. 29

6. The NMT transgene preserves podocyte number. .31

7. The Nmt transgene improves podocyte ultrastructure of ADR-injected mice ....33 8. Comparison of glomerular volume in ADR-treated FVB mice (FVB-ADR), ADRtreated Nmt mice (Nmt-ADR), control FVB mice (FVB-Control) and control Nmt mice (Nmt-Control). .35 


\section{Chapter II}

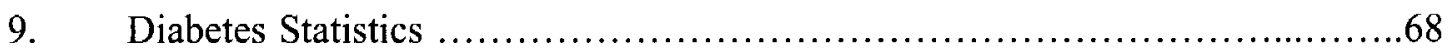

10. Developmental changes in albuminuria and gene expressions..........................70

11. Top 10 biological functions and/or diseases altered by both age and diabetes.... 72

12. Expression of inflammatory response genes identified by Ingenuity online database increased by age in diabetic kidneys................................... 74

13. Complement component 3 (C3) mRNA and protein are up-regulated in diabetic

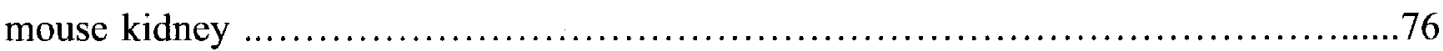

14. Increased VCAM1 expression in 8 month old diabetic kidney ..................79

15. Increased CD44 expression in 8 month old diabetic kidney ...................... 81

16. Increased CD68 expression and macrophage infiltration in 8 month diabetic kidney.

17. CD44 and VCAM1 are induced in different OVE26 tubules................ 85

18. Increased CYP27B1 expression in diabetic mouse kidney and increased serum level of 1,25-dihydroxy vitamin $\mathrm{D}$ in diabetic mouse .87

19. Fasn microarray results were validated by rtPCR using average fold change.......89

20. SREBF1 regulated genes with significantly altered gene expression in OVE26 kidney

21. Increased inflammatory genes expression at different stage of diabetes in OVE26 mice 


\section{CHAPTER I}

\section{METALLOTHIONEIN OVER-EXPRESSION IN PODOCYTES REDUCES ADRIAMYCIN NEPHROTOXICITY}

\section{INTRODUCTION}

\section{$\underline{\text { Adriamycin Induced Nephrotoxicity and Potential Mechanisms }}$}

Adriamycin (ADR) is commonly used to treat leukemia, lymphoma and other cancers. However, clinical use of ADR is limited due to its toxicity to kidney, heart and other organs. Its complex cytotoxic mechanisms [1] are known to include enzyme inhibition, DNA intercalation, reactive oxygen species generation [2] and inductions of apoptosis. ADR-induced nephropathy has been well characterized in rodents and demonstrated to include albuminuria, impaired glomerular function, glomerulosclerosis, morphological changes and other features[3,4]. In mice ADR nephropathy varies among strains, with $\mathrm{BALB} / \mathrm{C}$ mice being highly susceptible while C57BL/6J mice and most other strains are resistant [5].

Reactive oxygen species (ROS) are thought to be involved in the mechanism of ADR-induced kidney damage. ADR undergoes one-electron reduction catalyzed by flavin-containing enzymes [6] such as NADPH-cytochrome-P-450 reductase [7]. This reduction generates a semiquinone free-radical. In the presence of molecular oxygen, 
the semiquinone reduces oxygen to superoxide and regenerates intact ADR. The ADR semiquinone can also react with hydrogen peroxide to yield hydroxyl radical [8]. These toxic ROS react with cellular molecules, including nucleic acids, protein and lipids, causing cell damage. Most evidence for this free radical hypothesis comes from in vitro studies on cell lines, including reports that: (1) ADR increases ROS levels and lipid peroxidation [9] and (2) the finding that free radical scavengers such as $\mathrm{N}$-acetylcysteine [10], vitamin E [11] and superoxide dismutase [11] decrease the severity of ADR-induced damage. The free radical mechanism of ADR toxicity has been shown to apply to kidney cells. In cultured glomerular epithelial cells, ADR increased ROS production and produced cytoxicity [12]. ADR damage to cultured glomerular epithelial cells could be reduced by prior incubation with an ROS scavenger [12].

\section{$\underline{\text { Podocytes and Glomeruli }}$}

The nephron is the basic structure and functional unit of kidney. Each normal human kidney contains approximately one million nephrons, which help regulate the amount of water, salts, glucose, urea and other minerals in the human body. Each nephron consists of a filtering component (renal corpuscle) and a tubule that functions in reabsorption and secretion (renal tubule) (Figure 1A). The glomerulus surrounded by Bowman's capsule, constitutes a renal corpuscle and is essential for the filtering function of the nephron (Figure 1B). It is a capillary tuft resembling a twisted mass of tiny tubes through which the blood passes, exchanges water and waste, then has passed out of the 
Bowman's capsule as urine. Injury to gomeruli can interfere with its normal function and cause protein leakage into urine.

Glomeruli contain several cell types, endothelial cells, mesangial cells and podocyte cells. Podocytes surround the glomerular capillaries and are a component of the glomerular filtration barrier which prevents leakage of protein in the urine. Podocytes are needed to maintain a functional glomerular basement membrane [13] and healthy glomerular capillaries [14]. Destruction of podocytes can lead to massive proteinuria, which shows up in many nephropathy models including ADR [15] and diabetic nephropathy (DN) $[16,17]$. Therefore many studies have focused on podocytes damage to investigate their role in causing nephropathy.

\section{Adriamycin Damage to Podocytes}

In rodents model, ADR is rapidly cleared from the plasma after intravenous injection, deposited in tissue, mainly in kidney, which probably contributes to its great nephrotoxicity [18]. As described at the beginning of this Introduction, ADR promotes free radical generation. Animal studies had indicated that adriamycin induced nephrotoxicity is related to free radical generation and lipid peroxidation [19]. Supplement with antioxidants or increasing renal antioxidant levels such as GSH, could protect against adriamycin induced renal injury $[10,11,20]$.

Adriamycin could produce toxic effect to podocytes [21]. There are many in vitro and in vivo results demonstrating that Adriamycin treatment caused podocyte 
apoptosis [22], podocyte cytoskeleton structural reorganization [15] and loss of podocyte foot process [23].

We proposed that if podocyte damage of Adriamycin is direct and related to free radical formation then supplementation of podocyte with an antioxidant may reduce Adriamycin toxicity in kidney.

\section{$\underline{\text { Function of Metallothionein as an Antioxidant }}$}

Metallothionein (MT) is a low molecular weight (mammalian form is 6000-7000 Da), cysteine-rich, metal-binding (Zinc, Copper, Cadmium, Mercury, etc.) and highly inducible protein [24]. The induction of MT by oxidative stress has led to the speculation that MT might play roles in scavenging free radicals. There are many in vitro experiments demonstrating that MT can scavenge superoxide anions or hydroxyl radicals [25], phenoxyl radicals [26] and nitric oxide [27]. In yeast, increased MT levels are able to functionally substitute for antioxidant functions of copper/zinc superoxide dismutase [28]. During in vivo animal studies, MT is capable of scavenging many different types of ROS in pancreatic islets based on many laboratories previous findings $[29,30]$. MT also attenuates the cardiotoxicity of doxorubicin mainly due to its free-radical-scavenging properties [31]. Further, acute hepatic toxicity and hepatic oxidative stress have been reduced in MT transgenic mice. Conversely, increased intracellular oxidation and sensitivity to oxides has been observed in cells derived from mice lacking functional MT genes [32,33]. 
Mechanisms underlying the antioxidant function of MT are controversial. Some think that MT might function as an expendable target for oxidants due to its enriched cysteine residue structure. This was verified by Quesada and co-workers [34]showing that the sulfhydryl groups of MT isolated from HL-60 cells were oxidized by exposure of cells to $\mathrm{H}_{2} \mathrm{O}_{2}$.

Other investigators have suggested different antioxidant mechanisms for MT. The alternative proposed mechanisms underlying MT function might include its ability to complex transition metal $(\mathrm{Cu})$ [35], or altered Zinc and copper homeostasis [32]. Thomas et al reported that in the erythrocyte ghosts system, the primary determinant of MT protection from oxidants appeared to be metal dependent [36]. In addition, Zhou et al have shown that $\mathrm{Zn}$ protects from several organ injuries including alcoholic hepatic damage [37] independently of MT.

Overall, whether MT functions as a direct antioxidant due to its cysteine-enriched structure, or as an antioxidant indirectly by affecting two important metals, $\mathrm{Zn}$ and $\mathrm{Cu}$, or other possible mechanisms including conjunction with $\mathrm{GSH}[38,39]$ is still uncertain. However, based on a number of in vitro and in vivo experiments, the antioxidant role of MT is well documented.

\section{Prior Development and Studies of}

Transgenic Mice Over-expressing MT in Podocytes 
Our lab developed a transgenic line of mice (called NMT mice) with the antioxidant protein metallothionein (MT) over-expressed in podocytes [40]. We demonstrated that this line of mice was significantly protected from diabetic nephropathy. In severely diabetic mice at 4 month age, MT over-expression produced a $70-90 \%$ reduction in 24 hour albumin excretion and also reduced podocyte damage, as indicated by more podocytes per glomerulus and a higher density of podocyte foot processes.

Since MT possesses potent antioxidant action and ROS are thought to be the cause of ADR induced kidney damage, we elected to test whether MT could also reduce ADR nephrotoxicity. MT protects from ROS due to its very high thiol content. Our prior work in pancreatic beta cells [30] and cardiomyocytes [41] indicated that transgenic over-expression of MT scavenges a broad range of ROS. Importantly, we previously demonstrated that cardiac over-expression of MT protected the heart against ADR-induced cardiotoxicity [42]. These results indicated that MT would be a good antioxidant to protect against ADR nephropathy.

Podocytes are a glomerular cell-type sensitive to ADR cytotoxicity [15] and podocytes are critical to maintaining normal glomerular structure and function. Therefore, in this project we tested whether targeted over-expression of MT protein in podocytes could both reduce podocyte damage and decrease ADR nephropathy. 


\title{
METHODS AND MATERIALS
}

\begin{abstract}
Animals
Our lab produced transgenic mice with podocyte-specific over-expression of MT on the FVB background. The transgene designated Nmt contained $8300 \mathrm{bp}$ of the podocyte-specific mouse nephrin promoter (Dr Moeller, University of Michigan) ligated to a 2400 bp fragment containing the human MTII gene [29]. Podocyte-specific over-expression of MT was evaluated by immunohistochemistry and western blotting of glomerular protein with an MT-specific antibody. All mice were housed in ventilated cages at the University of Louisville Research Resource Center with free access to water and standard mice diet. All animal procedures adhered to the guidelines of the National Institutes of Health Guide for the Care and Use of Laboratory Animals and were approved by the University of Louisville Institutional Animal Care and Use Committee.
\end{abstract}

\section{Chemicals}

Adriamycin (Doxorubicin hydrochloride, $2 \mathrm{mg} / \mathrm{ml}$ ) was purchased from Sigma-Aldrich (St. Louis, MO). WT-1 antibody (1:50; rabbit polyclonal) was purchase from Santa Cruz Biotechnology (Santa Cruz, CA). MT antibody (1:40; mouse monoclonal) was purchased from DAKO (Glostrup, Denmark). Oregon Green 488 phalloidin was purchased from Invitrogen (Carlsbad, CA). Urine albumin ELISA kit 
was purchased from Bethyl Laboratories (Montgomery, TX). All other chemicals and solvents were of analytical grade.

\section{Experimental protocol}

To induce adriamycin (ADR) nephropathy on FVB background mice, the first step was to choose an appropriate ADR dose because ADR's effect is different from strain to strain. We tested three doses, $9 \mathrm{mg} / \mathrm{kg}$ body weight, $11 \mathrm{mg} / \mathrm{kg}$ body weight and $13 \mathrm{mg} / \mathrm{kg}$ body weight. These tests indicated that $9 \mathrm{mg}$ and $11 \mathrm{mg}$ could induce microalbuminuria on the FVB strain whereas the $13 \mathrm{mg}$ dose killed some mice right after injection. Therefore we chose the $11 \mathrm{mg} /$ body weight dosage for our experiments.

Two groups of mice, the FVB control group and the NMT transgenic group (15 male in each group), received the $11 \mathrm{mg} / \mathrm{kg}$ body weight dosage of ADR through tail vein injection. Twenty-four hour urine albumin excretion was measured and compared between the two groups at fixed time points; 5 days, 1 week, 2 weeks, 3 weeks and 4weeks. Four mice in both groups were sacrificed at the $5^{\text {th }}$ day after ADR treatment for renal pathology and immunohistochemistry studies. For control samples, we sacrificed four untreated FVB mice and four untreated NMT transgenic mice.

\section{Tail Vein injection of ADR}

Prepares the Adriamycin solution in saline solution to a final concentration of $2 \mathrm{mg} / \mathrm{ml}$. The mouse is placed into the barrel of a mouse restrainer and the restrainer is adjusted to make sure that mouse cannot move. The mouse tail is placed into a $50^{\circ} \mathrm{C}$ 
water bath to make it swollen. After $2 \sim 3 \mathrm{~min}$, one of the two lateral veins of the tail is located and a syringe needle is inserted into the vein. The required amount of dosage is smoothly injected.

\section{$\underline{\text { Urine collection and measurement of albuminuria }}$}

Twenty-four hour urine was collected using mouse metabolic cages at selected time points after ADR injection (5days, 1 week, 2 weeks, 3 weeks and 4 weeks). Mouse urine volume was increased by including 10\% Glucerna (Abbott Laboratories) in the drinking water. This produces a larger urine volume and allows for a more complete recovery of 24 hour urine samples.

Urine albumin was measured by commercial ELISA kit from Bethyl company. Urine albumin levels were also assayed before ADR injection as the zero day control point, from which we can see how much effect ADR has on urine albumin excretion.

\section{F-actin immunofluorescence assay of hydrogen peroxide injury to podocytes}

Cultured glomeruli were used in order to directly expose podocytes to oxidative injury and to be able to identify podocytes. In brief, cultured glomeruli were obtained by the following procedure: Glomeruli were purified from normal or transgenic mice by the Dynal beads perfusion procedure [43]. Glomeruli were then plated on glass coverslips in DMEM/F12 media for $4-5$ days at $37^{\circ} \mathrm{C}$ in $95 \%$ air, $5 \% \mathrm{CO} 2$. During this period podocytes extended out as monolayers from the centre of the glomerular tuft. 
After 16 hours treatment with $880 \mathrm{uM}$ hydrogen peroxide cells were fixed in $3.7 \%$ formaldehyde in sodium phosphate buffer for $10 \mathrm{~min}$ at room temperature and then permeabilized with $0.1 \%$ Triton $\mathrm{X}-100$ in sodium phosphate buffer for $3-5$ min. Podocytes were stained with antibody to the podocyte-specific marker WT1 (1:50; rabbit polyclonal, Santa Cruz Biotechnology, Santa Cruz, CA). F-actin was detected using Oregon Green 488 phalloidin (Invitrogen, Carlsbad, CA) diluted 1:40 in sodium phosphate buffer. The mounted cells were then photographed on a Nikon E600 fluorescent microscope. Images were rated by a blind observer for location and sharpness of F-actin filaments. This part of work was done by shirong zheng in Dr Paul. N Epstein's lab.

\section{$\underline{\text { Histopathological studies }}$}

Kidneys removed from anesthetized mice were immediately cut in half and fixed in $10 \%$ formaldehyde in $0.1 \mathrm{M}$ PBS ( $\mathrm{pH} 7.2$ ), and then transferred to $70 \%$ ethanol after 24 hours. The kidney tissue was then dehydrated in ascending concentrations of isopropanol and finally cleared in xylene and then embedded in paraffin. Blocks were sectioned at $5 \mu \mathrm{m}$ thickness. Prior to histochemical staining sections were cleared in xylene and rehydrated. Sections stained with hemotoxylin and eosin (HE), periodic acid Schiff (PAS) and trichrome were used to evaluate the general structural changes in glomeruli and tubules and for calculation of glomerular volume.

Stained sections were viewed under a light microscope and images were recorded at $400 \mathrm{X}$ magnification. The cross-sectional area of the glomerular tuft (AG) was determined from outlines of the tuft using the program Adobe Photoshop 7.0. 
Glomerular volume (VG) was calculated from the cross-sectional area using the formula $\mathrm{VG}=\beta / k(\mathrm{AG}) 3 / 2$, where $\beta=1.38$ is the shape coefficient for a sphere and $k=1.1$ is the size distribution coefficient $[44,45]$.

\section{$\underline{\text { Immunohistochemistry analysis }}$}

Formalin-fixed-paraffin-embedded sections were stained with antibody to the podocyte specific marker WT-1(1:50; rabbit polyclonal, Santa Cruz Biotechnology, Santa Cruz, CA) and for MT (1:40, mouse, monoclonal, DAKO). To quantify podocyte numbers, on each section we picked 20 glomeruli randomly and counted the WT-1 positive cells under the light microscope. Podocyte staining and quantification were performed on 4 groups of mice: FVB mice 5 days after ADR-treatment, NMT mice 5 days after ADR-treatment, FVB mice without ADR treatment and NMT mice without ADR treatment. Each group consisted of 4 mice. These counting studies were done by an observer blind to the identity of the sections.

\section{Electron microscopy}

Tissues from ADR treated mice and control FVB mice were used. Mice were deeply anaesthetized with intraperitoneal injection of ketamine $(100 \mathrm{mg} / \mathrm{kg})$ and xylazine ( $32 \mathrm{mg} / \mathrm{kg}$ ) then perfused through the heart with Tyrode solution, followed by a fixative of $1 \%$ paraformaldehyde and $3 \%$ glutaraldehyde in $0.1 \mathrm{~m}$ sodium phosphate buffer, pH 7.4 (PB). The kidneys were removed, weighed and decapsulated. They were then sliced longitudinally and the medulla from each slice was removed and cortical strips were cut into $1 \mathrm{~mm}^{3}$ tissue blocks. The blocks from each kidney were selected by 
unbiased technical personnel and placed into cold fixative overnight and then the selected blocks were post-fixed in $2 \%$ osmium tetroxide, dehydrated with an ethanol series and embedded in Durcupan resin (Ted Pella Co.). Thick sections $(250 \mathrm{~nm})$ were cut and stained by toluidine blue for light microscope observation, ultra-thin sections ( $70-80 \mathrm{~nm}$, silver-gray interference colour) were cut serially using a diamond knife. To avoid examining the same cells on multiple sections, every $10^{\text {th }}$ section was collected on Formvar-coated copper slot grids. Sections were then stained with $10 \%$ uranyl acetate in methanol for $30 \mathrm{~min}$ before examination with the transmission electron microscope.

\section{$\underline{\text { Statistical analysis }}$}

Values are expressed as mean $\pm \mathrm{SE}$. Statistical analysis was performed using Microsoft-Excel and Sigma-Stat software. Significance of differences was determined by two-tail $\mathbf{t}$ test for single comparisons. Two way analysis of variance (ANOVA) with Holm-Sidak post-hoc test was used for multiple comparisons with genotype and ADR injection used as the two factors. P-values less than 0.05 were considered statistically significant. 


\section{RESULTS}

\section{Changes of Urinary albumin excretion in FVB mouse after ADR treatment}

Initial dose- testing experiments between 9 and $13 \mathrm{mg} / \mathrm{kg}$ bodyweight $\mathrm{ADR}$ in wild-type FVB male mice suggested that a dose of $11 \mathrm{mg} / \mathrm{kg}$ adriamycin produced renal injury characterized by albuminuria and abnormal glomerular morphology. The lower dose of $9 \mathrm{mg} / \mathrm{kg}$ bodyweight produced less nephropathy while a higher dose of $13 \mathrm{mg} / \mathrm{kg}$ bodyweight produced more than $50 \%$ death rate. Therefore we chose $11 \mathrm{mg} / \mathrm{kg}$ bodyweight as the right dose for establishing ADR-injected nephropathy in FVB mice.

We checked 24-h urine excretion of albumin in FVB mice 5 days after ADR injection. This time point was chosen based on the results of Wang et al. [3], who reported that albuminuria increases 5 days after ADR injection. There was a 2-3-fold, significant elevation of urine albumin 5 days after ADR treatment (shown in Figure 1). This showed that ADR treatment injured kidneys of FVB mice.

\section{Expression of MT in Nmt transgenic and FVB control mice}

Oxidative stress has been reported to play an important role in Adriamycin (ADR)-induced nephropathy; and some antioxidant treatments have shown efficacy against ADR nephrotoxicity. Metallothionein is a low molecular weight, cysteine-rich, inducible protein, which is capable of scavenging many different types of ROS. Our lab developed a transgenic mouse line in FVB mice designated Nmt, which we have recently described [40]. In Nmt mice MT is over-expressed in podocytes using the podocyte-specific nephrin promoter (a more complete description of the Nmt transgene is 
contained in Zheng et al. [40]). The morphology of Nmt glomeruli appears normal and MT staining is clearly increased in Nmt glomeruli compared to FVB glomeruli, as shown in Figure 2. Also, elevated MT staining appears to be in the same cells that stain for WT1, illustrating that the increase in MT content is in podocytes. Using Nmt mice we demonstrated that over-expression of MT in podocytes protects the diabetic mouse model OVE26 from albuminuria and reduces injury to podocytes and glomeruli [40].

\section{In vitro protection of podocytes against ROS by MT overexpression}

We next determined if MT over-expression protected transgenic podocytes from oxidative damage. Because podocytes are less than $20 \%$ of glomerular cells we needed a histological procedure that would allow us to identify both injury to cells and which cells were podocytes. To achieve this we examined the effect of $\mathrm{H}_{2} \mathrm{O}_{2}$ on cultured glomeruli from transgenic and control mice. Cultured glomeruli were exposed to $880 \mu \mathrm{m} \mathrm{H} \mathrm{H}_{2} \mathrm{O}_{2}$ for $16 \mathrm{~h}$. They were then stained for F-actin using Oregon Green 488 phalloidin to examine cell injury.

The morphology and fragmentation state of F-actin filaments provides a marker for the health of many cultured cell-types [46,47], including podocytes [48]. The podocytes in the cell population were identified by staining for the podocyte marker WT1. Both F-actin filaments and WT1 were then examined by fluorescence microscopy. In podocytes, we observed that F-actin filaments were less sharply defined after $\mathrm{H}_{2} \mathrm{O}_{2}$ treatment (Figure 3). Also the filaments were localized less along the cell boundary and more towards the nucleus, which is similar to the findings of Huot et al. [46]. Figure 3 also shows that most Nmt podocytes were less susceptible to the 
disruption by hydrogen peroxide than control podocytes. More Nmt podocytes retained well-organized longitudinal stress fibre structure. Semi-quantitive studies of F-actin morphology after $\mathrm{H}_{2} \mathrm{O}_{2}$ treatment confirmed our observations that podocytes over-expressing MT were protected against $\mathrm{H}_{2} \mathrm{O}_{2}$-induced oxidative injury at the F-actin level.

\section{MT over-expression reduces ADR-induced albuminuria}

Based on our hypothesis that ADR nephrotoxicity would be attenuated by the MT-transgene, we measured 24-h urine albumin excretion following ADR injection in a group of non-transgenic FVB mice and a group of transgenic Nmt mice (Figure 4). In FVB mice, urinary albumin excretion (UAE) was elevated by the $5^{\text {th }}$ day after ADR injection and tended to increase out to 21 days post-injection. Nmt mice also had elevated UAE by 5 days post-injection, but they tended towards recovery much more rapidly than FVB mice. UAE in Nmt mice was significantly lower than in the FVB mice at 5,21 and 28 days after ADR injection.

\section{Podocyte staining and quantification}

In order to see if MT over-expression helped maintain podocyte numbers, we counted the number of podocytes per glomerular cross-section in untreated and ADR-treated FVB and Nmt mice (Figure 5). Podocytes were identified by staining with an antibody against the podocyte marker WT1. Mice were sacrificed 5 days after ADR injection for podocyte counting. As shown in Figure 5, ADR treatment produced a significant $(p<0.05)$ reduction in podocyte number in FVB mice of $\sim 20 \%$. However, 
in Nmt mice ADR treatment did not significantly reduce podocyte number and the Nmt-ADR mice had significantly more podocytes per glomerulus than FVB-ADR mice.

\section{Podocytes ultra-structure by electron microscopy}

Podocytes ultra-structure was further examined using electronic microscopy. Compared to the distinct brush-like structure of podocytes foot processes shown in control mice (Figure 6A and D), fusion of podocytes foot processes developed in FVB mice at 5 days after ADR injection (Figure 6B and E). Nmt mice podocytes tended to retain relatively normal ultra-structures (Figure 6C and F), which means the NMT podoctes retained the relatively clearly defined brush like structures after ADR treatment. These results were representative of two Nmt and two FVB mice treated with ADR.

\section{Glomerular volume calculation}

Glomerular volume was estimated by light microscopy on H\&E stained kidney sections according to the mathematical model of Weibel and Gomez $[44,45]$. FVB mice receiving ADR showed a trend towards reduced glomerular volume compared to

control FVB mice (Figure 7), though the difference did not reach significance $(p=0.117)$. In Nmt mice glomerular volume was not reduced at all by ADR injection and the glomerular volume of NMT-ADR mice was significantly greater than that of FVB-ADR mice $(p<0.05)$ (Figure 7). 


\section{DISCUSSION}

In this study, we demonstrated that inbred FVB mice are susceptible to ADR-induced renal damage. This was evident as decreased podocyte number, reduced glomerular volume and significantly increased albuminuria. Furthermore, when we tested ADR toxicity in Nmt transgenic mice [40] that over-express MT specifically in podocytes, all parameters tested for ADR-induced nephropathy were significantly reduced. These findings show that podocytes are a direct target of ADR damage and that protection of podocytes by increasing expression of MT reduces ADR nephropathy.

The FVB strain of mice was selected for this study because it is the strain that Nmt transgenic mice was developed on. However, Zheng et al. [40] reported that among many strains tested, including FVB, only BALB/C mice were susceptible to ADR nephropathy. In contrast to their findings we observed that FVB mice were sensitive to ADR: ADR treatment increased albuminuria more than 2-fold, to $\sim 0.75 \mathrm{mg} / 24 \mathrm{~h} . \quad$ ADR also affected glomerular structure: Glomeruli tended to be smaller, as has been reported in ADR treated rats [49], and podocyte number per glomerular section was reduced. We believe that the reason our conclusion about ADR toxicity to FVB mice was different from that of Zheng et al. is that BALB/C mice are much more sensitive: $\mathrm{ADR}$ treatment increases albuminuria more than 20-times in BALB/C mice [50] but only two times in FVB mice. Also, ADR-induced morphological changes in FVB mice are less obvious and more difficult to measure than morphological changes in BALB/C mice. Both our morphological and albuminuria studies show that FVB mice are damaged by ADR, albeit 
to a lesser extent than in $\mathrm{BALB} / \mathrm{C}$ mice. The methods we used to detect ADR damage by albumin ELISA were more sensitive than the methods used by Zheng et al. and we believe that is why we observed ADR-induced injury to FVB mice when Zheng et al. did not. Zheng et al. identified the DOXNPH haplotype of BALB/C mice as critical to this strain's sensitivity to ADR. FVB mice do not carry this haplotype. It is possible that other strains of mice, in addition to FVB, that do not have the BALB/C haplotype also exhibit modest sensitivity to ADR.

The renal cell-type(s) sensitive to ADR are uncertain. A number of renal cells are damaged by ADR treatment, including tubular epithelial cells [49] and glomerular cells[51]. Since different renal cell-types interact in vivo it is difficult to determine which cells are damaged directly and which are damaged indirectly. Glomerular podocytes are an important determinant of proteinuria. They are an essential component of the normal glomerular filtration barrier and injury to podocytes produces albuminuria. If ADR damages podocytes in vivo then this could cause the prominent proteinuria of ADR nephropathy. In vitro experiments with cultured podocytes indicate that they are sensitive to ADR toxicity [52]. To assess whether podocytes are a direct site of ADR injury in vivo, we protected them by targeted over-expression of MT using the transgene Nmt, which uses the podocyte-specific nephrin promoter. Our results show that podocytes are a direct target of ADR toxicity, since the transgene was not expressed in any other cell type.

The mechanism of toxicity by ADR has not been clearly established in the kidney. It is widely supposed that a major cytotoxic mechanism of ADR is to increase 
ROS generation. MT is a potent antioxidant and our prior work demonstrated that transgenic over-expression of MT in pancreatic beta cells and cardiomyocytes [30,41] increases scavenging of a broad range of ROS including peroxynitrite, superoxide and hydrogen peroxide. The in vitro experiments needed in this study to specifically examine podocyte damage showed that MT over-expression protected podocytes from oxidative injury. Therefore, MT protection against nephrotoxicity induced by ADR provides stronger evidence that ROS are a cause of ADR toxicity. However, because MT has actions in addition to scavenging ROS [53] and because we did not demonstrate changes in oxidative damage in podocytes, it is possible that MT reduced ADR toxicity by mechanisms other than reduced oxidative stress.

Protective effects of MT over-expression were evident by morphological analysis. Five days after ADR treatment, Nmt glomeruli were larger and had more podocytes than FVB glomeruli. The ADR-induced decline in podocyte number was completely eliminated by the Nmt transgene. This action of MT may have been due to preventing ADR-induced podocyte death or it may have been due to reducing podocyte detachment. ADR also produced injury to podocytes' ultra-structure. Electronic microscopy studies showed that adriamycin caused podocyte foot process effacement in FVB mice and this damage appeared to be reduced by the NMT transgene. The fact that MT over-expression in podocytes provided protection indicates that the injury was a direct action of ADR on the podocyte and that the damage was mediated through ROS toxicity. The mechanism behind the trend to reduced glomerular volume after ADR treatment is less clear. It is an abnormality that has also been observed in glomeruli of ADR-treated rats [49]. The reduction in podocyte number is not sufficient to explain 
the reduction in total glomerular volume, because podocytes represent too small a fraction of the glomerulus. Since MT podocyte protection eliminated the reduction in volume, it is probable that the decrease in glomerular volume developed secondary to podocyte injury. Podocyte damage has been shown to have significant effects on other glomerular cells in vivo, such as mesanagial cells [54,55].

The clearest effect of MT over-expression was that Nmt mice had less albuminuria after ADR injection. The initial rise in albuminuria at 5 days post-treatment was significantly less in Nmt mice and albuminuria rapidly declined in Nmt mice, whereas it continued to rise in FVB mice. This result is consistent with the protection observed for podocyte number and demonstrates that the cause of ADR-induced albuminuria in FVB mice is injury to the podocyte.

In summary, our results show that ADR produce nephropathy in FVB mice and that MT protection of one glomerular cell type, the podocyte, is sufficient to protect all components from ADR nephrotoxicity. 


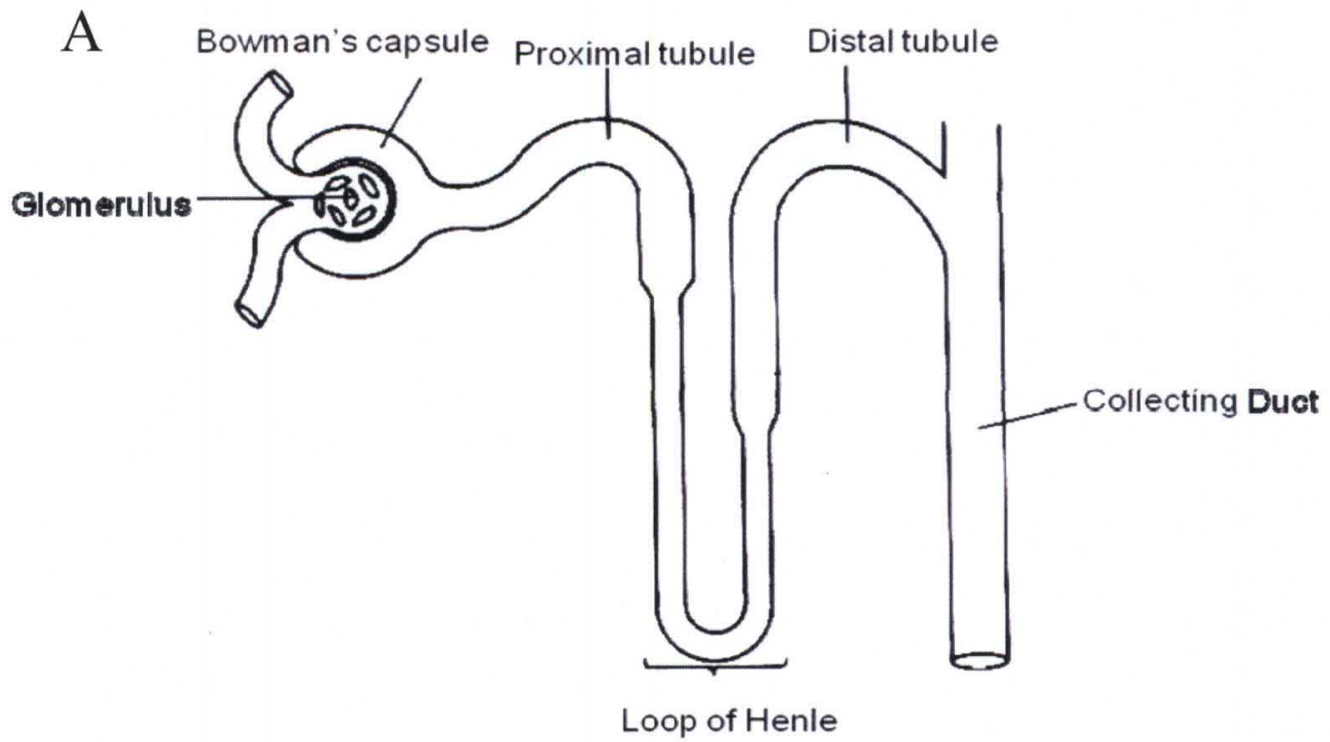

3

\section{Bowman's Capsule}

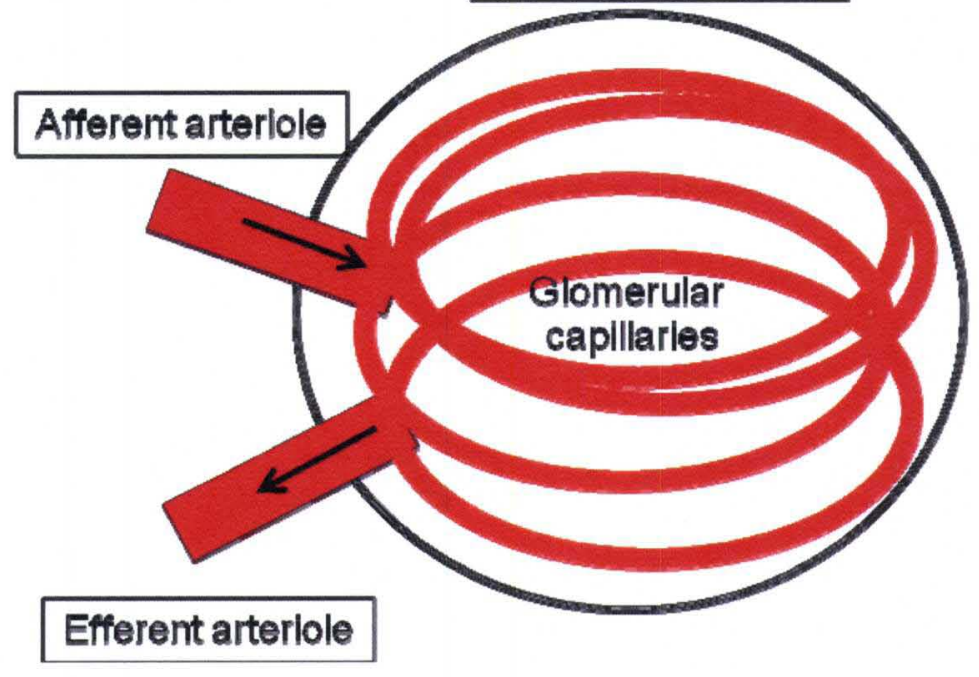


Figure 1. Schematic diagram of Nephron. A) A nephron consists of glomerular capsule, proximal convoluted tubule, loop of Henle, distal convoluted tubule and collecting duct. B) Glomerulus is located within the Bowman's capsule. Blood is transported into the Bowman's capsule from the afferent arteriole, filtered through the glomerulus and passed out via the efferent arteriole. While not shown in this diagram, the glomerular capillaries are completely surrounded by podocytes that form a layer of the filtration barrier. 


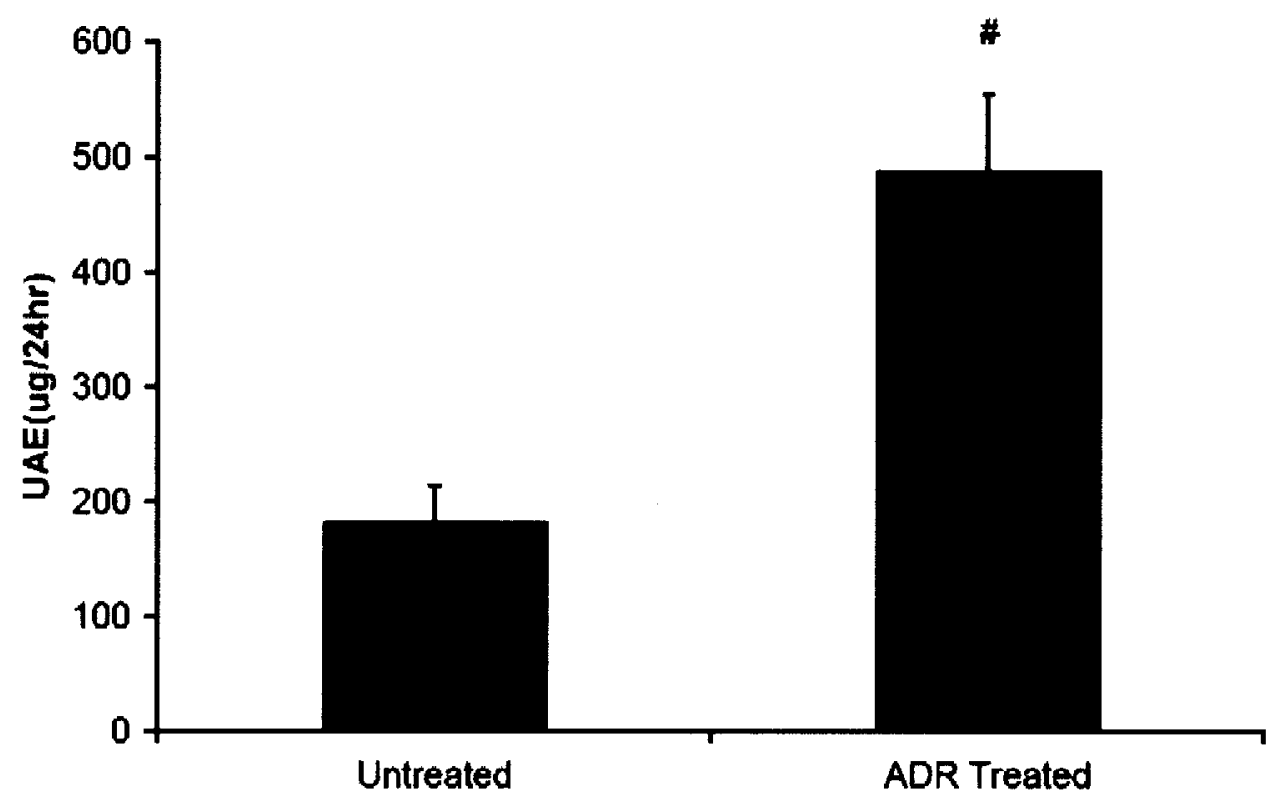


Figure 2. ADR increases urine albumin (UAE) and total protein excretion in FVB

mice. The graph shows 24-h urine albumin excretion from FVB mice before (untreated) and 5 days after ADR treatment (values are the means \pm SE of 15 mice, \# indicates $p$ $<0.01)$. 


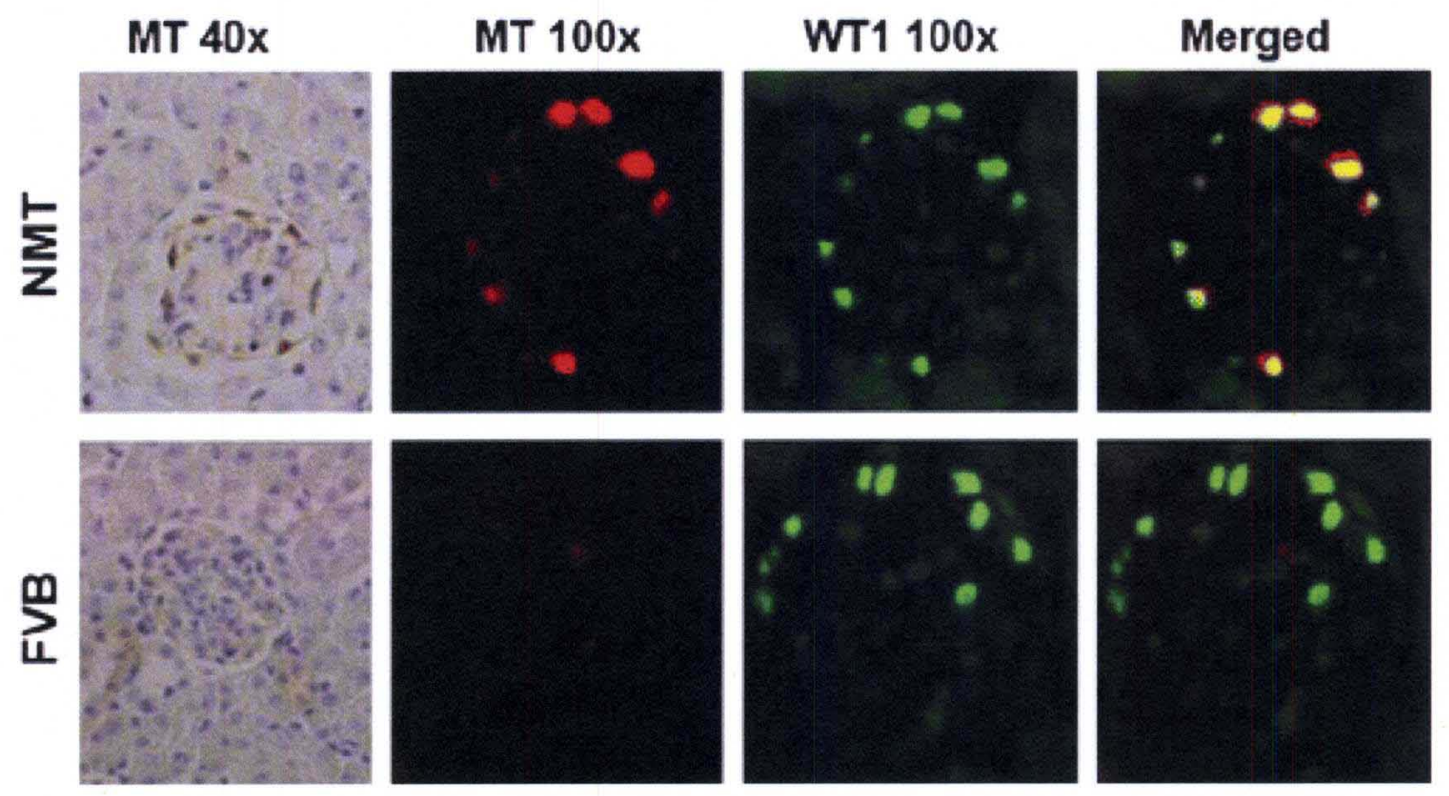


Figure 3. Expression of MT in Nmt transgenic and FVB control mice. Light microscopy images at left show normal morphology in Nmt glomeruli. MT staining with DAB chromogen is indicated by brown colour in these panels. The fluorescent images show double-staining for MT (red) and WT1 (green). In the merged image (yellow) indicates colocalization of MT and WT1. Original light micrographs were taken at $40 \times$ and fluorescent images were taken at $100 \times$ magnification. 

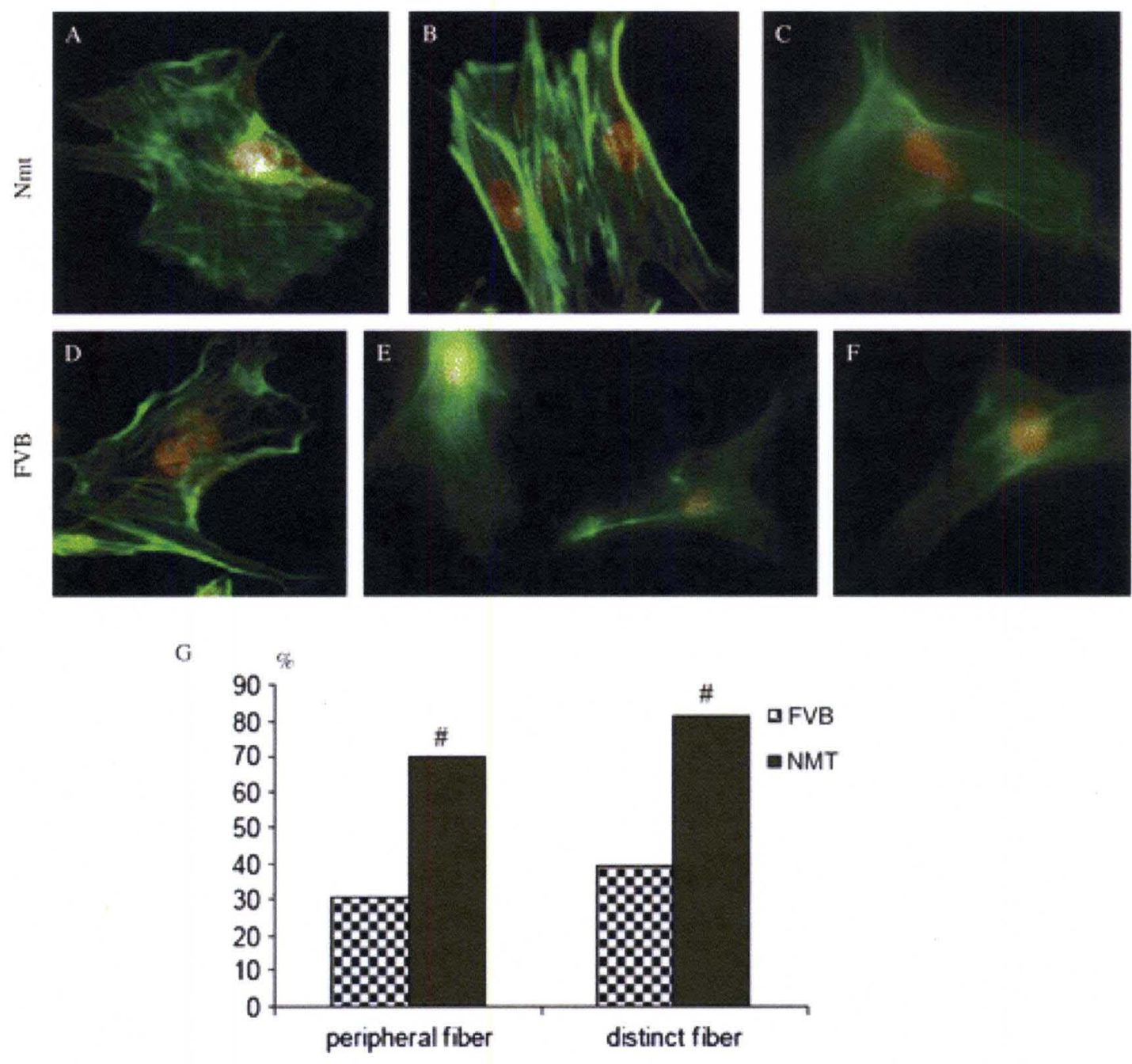
Figure 4. F-actin filaments are resistant to $\mathrm{H}_{2} \mathrm{O}_{2}$ in $\mathrm{Nmt}$ podocytes. Green is Oregon green phalloidin staining for F-actin. Red is WT1 staining for identification of podocyte nuclei. (A and D) Untreated Nmt and FVB podocytes. (B and C) Two examples of $\mathrm{Nmt}$ podocytes after $16 \mathrm{~h}$ of $880 \mu \mathrm{m} \mathrm{H} \mathrm{H}_{2} \mathrm{O}_{2}$ exposure. (E and F) Two examples of FVB podocytes after $\mathrm{H}_{2} \mathrm{O}_{2}$ exposure. In many $\mathrm{Nmt}$ podocytes (B) the F-actin filaments retained their distinct structure and peripheral location after $\mathrm{H}_{2} \mathrm{O}_{2}$ exposure. (G) Semi-quantitative analysis of F-actin morphology after $\mathrm{H}_{2} \mathrm{O}_{2}$ exposure. F-actin fibres were rated by a blind observer whether they did or did not retain peripheral localization and whether or not the fibres were clearly defined (distinct). Scoring is of 20 podocytes from three separate glomerular preparations per group. \# indicates that Nmt is higher that FVB $(p<0.02)$ by Chi-square test. 


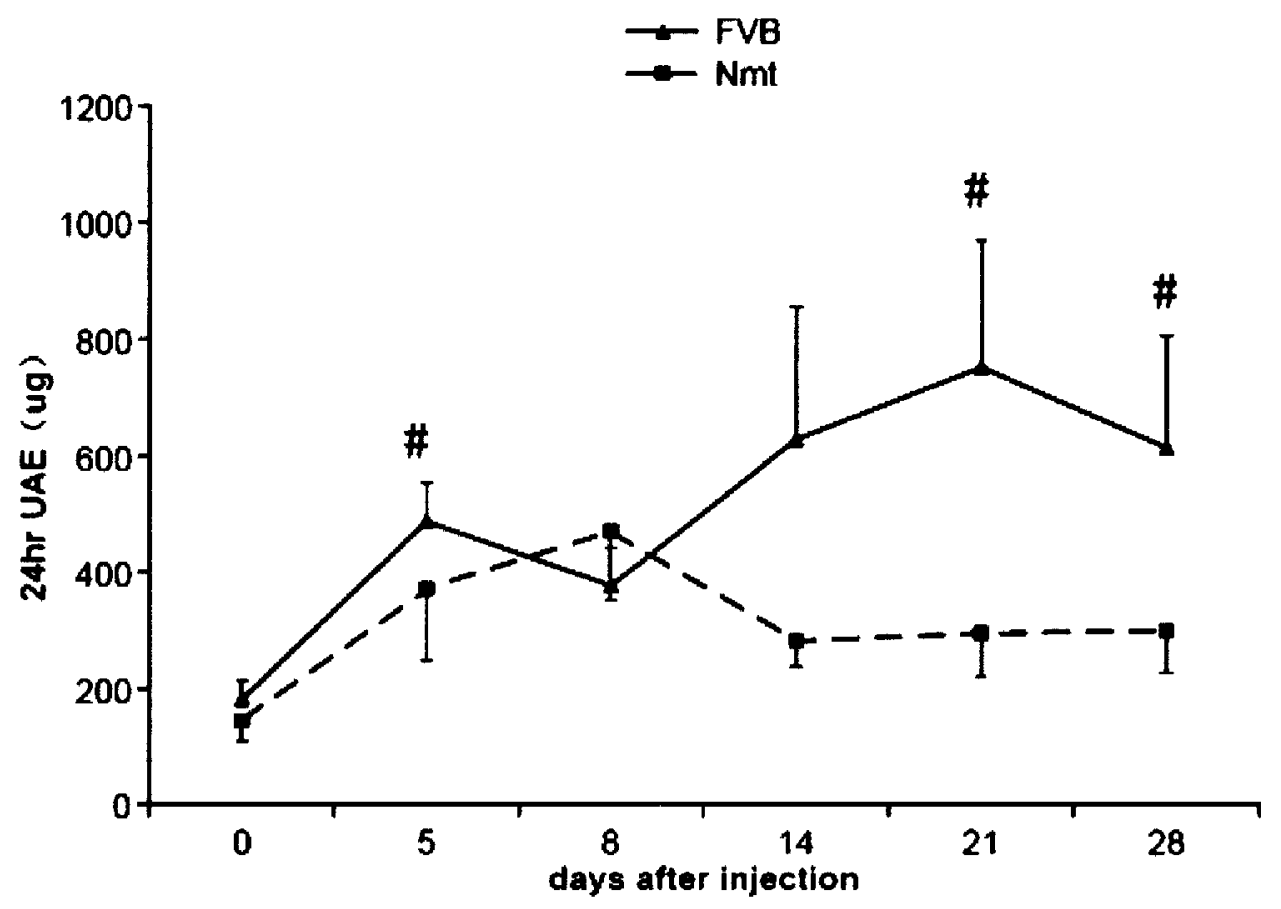


Figure 5. MT over-expression reduces ADR-induced albuminuria. Twenty-four hour urine albumin excretion plotted against time after ADR injection. Values are the mean \pm SE. \# indicates $p<0.05$ for the difference between Nmt and FVB at that time point by two-way ANOVA ( $n \geq 6$ mice for FVB group, $n>8$ mice for Nmt group). 

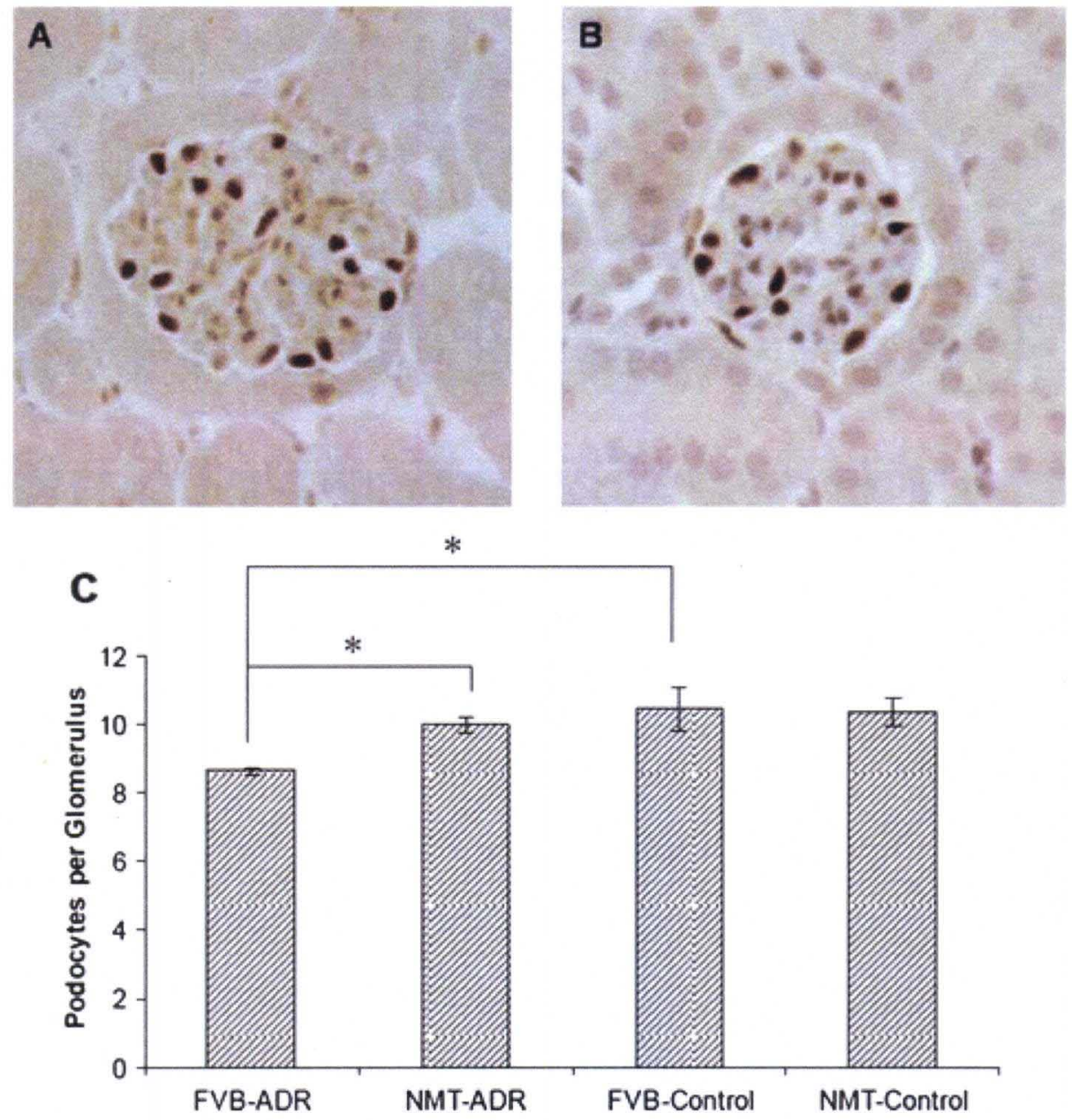
Figure 6. The NMT transgene preserves podocyte number. (A) FVB-control and (B) FVB-ADR show typical WT1 staining of control and ADR-treated FVB glomeruli. Brown staining indicates podocyte nuclei. (C) Quantitative comparison of podocyte number among different groups. Kidney samples were taken 5 days after ADR injection. The asterisks indicate that podocyte number in ADR-treated FVB mice is lower than in either ADR-treated Nmt or non-treated FVB glomeruli ( $p<0.05$ by two-way ANOVA, $n \geq 4$ mice per group). Vertical bars are the SEM. 


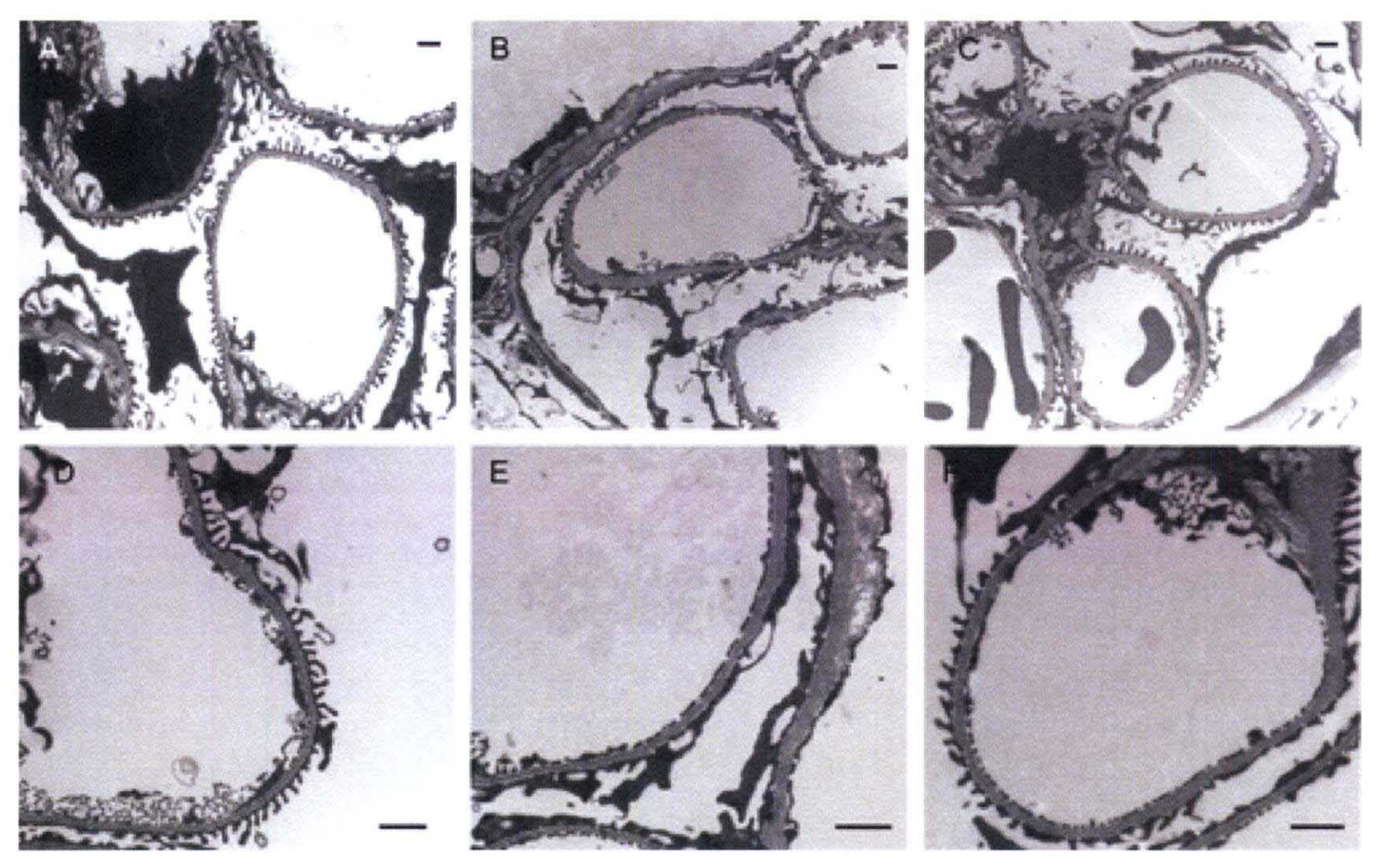


Figure 7. The Nmt transgene improves podocyte ultrastructure of ADR-injected mice. (A and D) Normal structure of podocytes foot processes in a FVB mouse without ADR injection at low $(5600 \times)$ and high $(9800 \times)$ magnification, respectively. (B) $4900 \times$ and (E) $8800 \times$ show effacement of podocytes foot processes in FVB mice 5 days after ADR injection. (C) $4900 \times$ and (F) $8800 \times$ show relatively normal foot processes in $\mathrm{Nmt}$ mice 5 days after ADR injection. (The scale bars on each panel represent $1 \mu \mathrm{m}$.) ADR results are representative of two mice per group. 


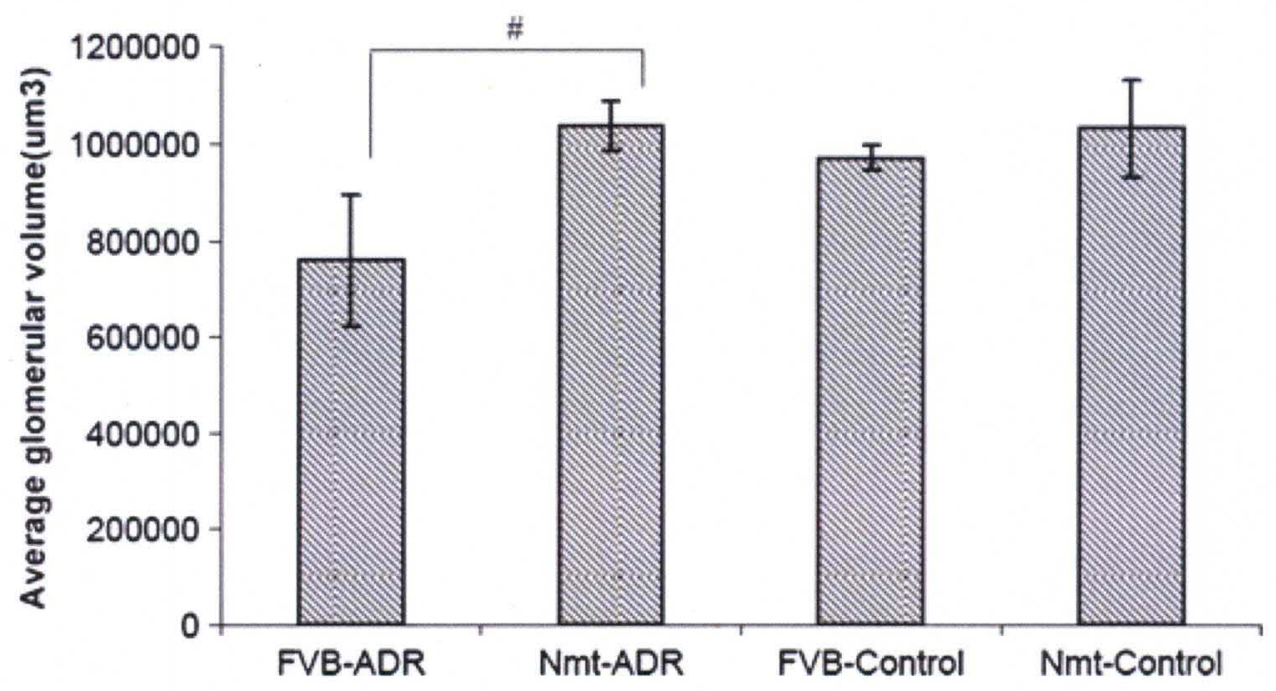


Figure 8. Comparison of glomerular volume in ADR-treated FVB mice (FVB-ADR), ADR-treated Nmt mice (Nmt-ADR), control FVB mice (FVB-Control) and control Nmt mice (Nmt-Control). The average volume of ADR treated FVB glomeruli was significantly less than the volume of ADR-treated Nmt glomeruli (\# indicates $p<0.05$ by two way ANOVA). Kidney samples were fixed 5 days after ADR injection. Average glomerular volumes for each group were determined from measurement of 80 glomerular cross-sections measured in four different mice of that group. Values are the mean \pm SEM. 


\section{CHAPTER II}

\section{GENE EXPRESSION DURING PROGRESSION OF DIABETIC NEPHROPATHY}

\section{INTRODUCTION}

\section{Diabetes and Diabetic Nephropathy (DN)}

Diabetes is a group of metabolic diseases marked by high blood glucose levels, resulting from defects in insulin production, insulin action or both. Diabetes is one of the leading causes of death in the United States and the world, it affects $7.8 \%$ of the population in the United States. About 1.6 million new cases of diabetes are diagnosed in people aged 20 years and older each year (fig 9A). Diabetes is a group of metabolic diseases marked by high blood glucose levels, resulting from defects in insulin production, insulin action or both. Diabetes can lead to serious complications such as heart attack (diabetic cardiomyopathy), kidney failure (diabetic nephropathy), blindness and nerve problems etc.

Diabetes is the most common cause of end stage renal disease (ESRD) [56], accounting for about 44 percent of new cases of kidney failure (fig 9B). In 2007, 48,871 people with diabetes began treatment for end-stage kidney disease in the United States. The basic mechanisms of Diabetic nephropathy (DN) are not well understood 
and research is restricted by limitations in available diabetic models. Current animal models of DN do not exhibit many of the key clinical features of advanced human DN such as severely reduced GFR and extensive interstitial fibrosis [57]. However it is possible that the processes leading to advanced $\mathrm{DN}$ are already underway in these diabetic animals but they fail to reach renal failure due to the many years required to produce the damage seen in diabetic patients.

\section{Diabetic Nephropathy and Inflammation}

Diabetic nephropathy has become the major cause of end stage renal failure, however the mechanism underlying the progression of renal injury still remains unclear. There is increasing evidence that links inflammation with development of DN. Recent data suggest that inflammatory markers such as interleukins and tumor necrosis factor (TNF)-alpha in the serum of patient with DN are increased [58,59]. Frederik et al has reported that inflammation marker (IL-6, fibrinogen, hs-CRP) were found as independent predictors of progression to DN in patients with diabetes and microalbuminuria [60].

In animal models of DN, there are also studies that suggest that inflammation plays an important role in the development of renal injuries in diabetes. Chow and co-workers [61] indicated that the inflammation marker ICAM-1 is a critical promoter of nephropathy in $\mathrm{db} / \mathrm{db}$ mice, which is a mouse model of type 2 diabetes, by facilitating kidney macrophage recruitment. In OVE26 mice model of diabetes and DN, produced by our lab, an increase of inflammation markers such as interleukins and chemokines in renal gene expression is also observed in the diabetic kidneys. 
These clinical findings and experimental studies support the role of inflammation in the development of DN. A further investigation of inflammatory pathways activated in DN may help discover important therapeutic targets for diagnosis and treatments for $\mathrm{DN}$.

\section{$\underline{\text { Vitamin D and renal inflammation in Chronic Kidney Disease }}$}

Vitamin D has now been recognized to possess immunomodulatory properties that are mediated by vitamin D receptor (VDR), which is found to be expressed on several immune cells, especially antigen-presenting cells such as macrophages, dendritic cells and both CD4+ and CD8+ T-cells [62,63]. Active vitamin $\mathrm{D}$ has also been reported to down-regulate the production of several inflammatory cytokines [64], the regulation is mediated through interference with nuclear transcription factor such as NF-kB [65].

Renal inflammation, characterized by the inflammatory cells infiltrating into glomerulus and tubulointerstitium, plays a role in the evolution of chronic kidney diseases (CKD) [66]. Several clinical studies discovered the declining renal function is closely related to the extent of inflammation in CKD patients [67]. Vitamin D deficiency is observed as an early pathological feature of CKD [68]. In nephropathy patients, there is a significant correlation between expression of CYP27B1, the rating limiting enzyme for formation of active vitamin D and renal inflammation [69]. Conversely, in CKD patients, active vitamin $\mathrm{D}$ treatment reduced proteinuria and all-cause mortality $[70,71,72]$. It has been proposed that the potential mechanism is related to the anti-inflammatory effect of vitamin $\mathrm{D}$ in CKD. 
Several lines of evidences support the anti-inflammatory role of vitamin $\mathrm{D}$ in

CKD. In mouse models of type 1 diabetes (T1D) and type 2 diabetes (T2D), supplementary vitamin D reduces renal inflammation and DN [73]. In mouse model of obstructive nephropathy, active vitamin D analogue inhibited renal inflammatory infiltration and expressions of proinflammatory cytokines [68]. Zehnder et al found in patients with kidney disease, there's a inverse correlation between renal inflammation and serum active vitamin D level [69]. The underlying mechanisms of vitamin D's anti-inflammatory activity is still needing further investigation, it has been suggested that the mechanism is through VDR mediated sequestration of NF-kB signaling [68].

\section{OVE26 Diabetic Mouse Model}

OVE26 mice were produced by introduction of a calmodulin transgene regulated by rat insulin promoter into FVB/NJ mice, which caused beta cell specific damage[74]. This beta cell impairment in OVE26 mice causes the mice to become diabetic within a week of birth and eventually develop severe hyperglycemia. The mice can survive over a year without insulin treatment because of sufficient residual insulin secretion. According to the criteria established by the NIDDK, our OVE26 mice show great potential to be a good model for type I diabetes. Compared to non-diabetic controls, OVE26 mice also exhibit albuminuria by 2 months of age and progress to significant albuminuria as the age goes up [16]. Severe interstitial fibrosis, mesangial 
expansion and glomerular basement membrane (GBM) thickness are also observed in the OVE26 model. GFR also shows a small reduction at 9 months age. For all of the reasons above, OVE26 mice seem to be a suitable model for us to investigate gene expression changes during the development of DN.

Our OVE26 mice survive at least one year so it provides an ideal model for analyzing the gene expression change during the chronic progression of the disease. Analyzing diabetic kidneys at different time points will be helpful to understand how the disease progresses, which changes are primary and what time points are most important. Currently we have run the microarray gene expression assay on whole kidney from 2 month old, 4 month old and 8 month old diabetic mice and FVB control mice.

\section{Microarray and DN}

Microarray technology evolved from Southern blotting, where fragmented DNA is attached to a substrate and then probed with a known gene or fragment. It is increasingly used by biologists to measure changes of gene expression level, to detect single nucleotide polymorphisms (SNPs), to genotype or resequence mutant genomes. The process of measuring gene expression via cDNA/cRNA is called expression analysis or expression profiling.

Chronic diseases like diabetes are likely to affect the gene expression profiles. Surrogate end points, such as changes in renal gene expression are needed to evaluate the progression of disease in animals. Gene expression studies can be used to identify individual protein targets or they can be used to recognize major signaling 
pathways activated in diabetic tissues. A number of genes and pathways have been identified in advanced DN of human kidney samples and also in kidneys from the Type 2 diabetic $\mathrm{db} / \mathrm{db}$ mouse model $[75,76]$. Studies on gene expressions will be useful for investigating the molecular pathways involved in development of DN. New gene chips available from Affymetrix allow for analysis of all the genes produced by DN mouse model. 


\title{
METHODS AND MATERIALS
}

\begin{abstract}
Animals
Our lab developed OVE26 transgenic mice on the FVB background by using a transgene to over-express calmodulin in pancreatic beta cells [74]. Normal female FVB mice and diabetic female OVE26 mice were sacrificed at 2, 4 and 8 months of age. Kidneys, serum and urine samples were harvested. Mice were housed in HEAP-filtered ventilated cages in the University of Louisville Research Resources Center under barrier conditions, with free access to water and Purina Mills \#5001 Laboratory Rodent chow. All animal procedures were approved by the Institutional Animal Care and Use Committee, which is certified by the American Association of Accreditation of Laboratory Animal Care.
\end{abstract}

\section{Chemicals}

RNA extracting reagent Trizol was purchased from Invitrogen Life Technologies (Carlsbad, CA); High-Capacity cDNA Archive Kit was purchased from Applied Biosystems (Foster City, CA); Taqman pre-made probes and reagents were purchased from Applied Biosystems (Foster City, CA); rabbit polyclonal anti-mouse CD44 was purchased from Abcam Inc (Cambridge, MA); biotinylated secondary antibodies and Vectastain $\mathrm{ABC}$ kit were purchased from Vector Labs Inc (Burlingame, CA); rabbit anti-mouse albumin antibody was purchased from Bethyl Laboratories (Montgomery, TX); FITC-conjugated goat anti-mouse C3 was purchased from MP Biomedicals (Cleveland, $\mathrm{OH}$ ), rat monoclonal anti-mouse $\mathrm{F} 4 / 80$ was purchased from Cell 
Sciences (Canton, MA), goat anti-mouse VCAM1 was purchased from R\&D Systems (Minneapolis, MN); 1,25-dihydroxyvitamin D ELISA kit was purchased from Immunodiagnostic System (Scottsdale, AZ).

\section{$\underline{\text { RNA isolation and Microarray procedures }}$}

Total RNA was prepared from flash frozen left kidney, excised from ketamine/xylazine anesthetized mice. The kidney was pulverized under liquid nitrogen and RNA extracted using Trizol reagent (Invitrogen, CA) following the manufacturer's protocol. The quantity of cellular RNA was determined by UV absorbance, and integrity monitored with an Agilent BioAnalyzer 2100 using nano- or pico-chips. Preparation of cDNA was carried out using the one-cycle cDNA synthesis kit with oligo-dT-T7 promoter primers (Affymetrix, Inc.). The cDNA served as template for T7 RNA polymerase transcription in the presence of biotin-labeled CTP and UTP. The cRNA was fragmented to a size range of 50-200 nucleotides. Probes were hybridized to Affymetrix MG-430 2.0 GeneChips.

Signal intensity data comparisons between control and diabetic samples at each age were compared using SAM 3.0 [77] and a minimal false discovery rate of $\mathrm{P}<0.05$. For comparison of multiple factors (age and diabetes) a two-way ANOVA of signal intensity was done with Partek Genomic Suite v5.2 (St.Louis, MO). Lists of significantly altered genes and fold change data were imported into Ingenuity Pathway Analysis (Redwood City, CA) for biological interpretation.

\section{$\underline{\text { RT-PCR }}$}


Single strand cDNA was synthesized from the extracted RNA using High-Capacity cDNA Archive Kit (Applied Biosystems, Foster City, CA) following the manufacturer's instructions. The cDNA was then amplified on a thermocycler $(7300$ Real time PCR system, Applied Biosystem) using commercially available Taqman reagents (Assay on demand, Applied Biosystem) for C3, Fasn and Hmgcr. $18 \mathrm{~S}$ ribosomal RNA was used for results normalization. The amplification profile used 40 cycles of denaturation at $95^{\circ} \mathrm{C}$ for $15 \mathrm{sec}$, primer annealing/extension at $60^{\circ} \mathrm{C}$ for $1 \mathrm{~min}$. The mRNA expression levels of the selected genes were normalized to $18 \mathrm{~s}$ ribosomal RNA in each sample. Relative expression ratio was calculated according to the $2^{-\Delta \Delta C T}$ method. Duplicate runs were performed on each sample.

\section{$\underline{\text { Immunohistochemistry }}$}

Kidneys removed from anesthetized mice were immediately cut in half and fixed in 10\% formaldehyde in $0.1 \mathrm{M}$ phosphate buffered saline (PBS, pH 7.2), and transferred to $70 \%$ ethanol after 24 hours in fixative. The kidney was then embedded in paraffin and sectioned at $5 \mu \mathrm{m}$. Following deparaffinization and hydration, the sections were subjected to antigen retrieval using $10 \mathrm{mM}$ citrate buffer ( $\mathrm{pH}$ 6.0) in a decloaking chamber (Biocare Medical, Concord, $\mathrm{CA}$ ) at $125^{\circ} \mathrm{C}$ for 5 minutes, then washed in PBS. For labeling of CD44, endogenous peroxidases were first blocked with 3\% hydrogen peroxide in water, then nonspecific binding was blocked with normal serum for 20 minutes at room temperature. The sections were then incubated 1 hour at RT with rabbit polyclonal anti-mouse CD44 (1:100, Abcam, Inc, MA), washed and then incubated with the biotinylated secondary antibody (Vectastain ABC kit, Vector Labs Inc, CA). 
Peroxidase activity was identified by reaction with 3,3'-diaminobenzidine (Vector Labs Inc, CA).

For immunofluorescence labeling, sections were first blocked with normal serum, then incubated overnight at $4^{\circ} \mathrm{C}$ with the following primary antibodies: rabbit anti-mouse albumin (1:500, Bethyl Laboratories, TX), FITC-conjugated goat anti-mouse C3 (1:100, MP Biomedicals, OH), rat monoclonal anti-mouse F4/80 (1:40, Cell Sciences, MA), rabbit polyclonal anti-mouse CD44 (1:100, Abcam, Inc, MA) or goat anti-mouse VCAM1 (1:10, R\&D Systems, MN). After washing in PBS, the sections (except for those with FITC-labeled C3) were incubated with the following secondary antibodies (1:100) for 1 hour at RT: anti-rabbit FITC or Cy3, anti-rat Cy3, anti-rabbit AMCA or anti-goat Cy3. Images were captured using a Nikon DS-Fil camera system with a Nikon E600 microscope.

\section{Generation of complement C3 RNA probe and in situ hybridization}

A probe designated $\mathrm{pC} 3-1-414$ was prepared from a plasmid containing a $5088 \mathrm{bp}$ cDNA insert of complement $\mathrm{C} 3$ in the multiple cloning site of the vector pCMV-SPORT6 (American Type Culture Collection, VA). The probe plasmid pC3-1-414 was constructed by cutting the original C3 plasmid with HindIII (HindIII cuts the C3 cDNA at position 414, 5056 and in the multiple cloning site of the pCMV-SPORT6 vector at position 743). The cut plasmid was religated leaving the first 414 bp of the C3 cDNA in the plasmid. Antisense digoxigenin- labeled C3 transcripts were produced by linearizing pC3-1-414 with SalI and transcribing with T7 RNA polymerase. Sense transcripts were produced by linearizing with HindIII and 
transcribing with SP6 RNA polymerase. Labeling was performed according to the manufacturer's instruction (Roche) and hybridization was done essentially as described [78]. After frozen sections were dried at $50^{\circ} \mathrm{C}$ for $15 \mathrm{~min}$, they were fixed in $4 \%$ paraformaldehyde, then treated with $2 \mathrm{ug} / \mathrm{ml}$ proteinase $\mathrm{K}$ at RT for $5 \mathrm{~min}$. Following a 1 hour prehybridization step, sections were then hybridized overnight at $65^{\circ} \mathrm{C}$ with $100 \mathrm{ul}$ hybridization buffer $(5 \mathrm{xSSC}, 5 \mathrm{xDenharts}, 250 \mathrm{ug} / \mathrm{ml}$ bakers yeast RNA, $500 \mathrm{ug} / \mathrm{ml}$ herring sperm DNA, $50 \%$ formamide) containing $100-200 \mathrm{ng} / \mathrm{ml}$ of digoxigenin-labeled probes. After washing three times in pre-warmed $0.2 \times S S C$ at $65^{\circ} \mathrm{C}$ and once with $0.2 \times S S C$ at $\mathrm{RT}$, the sections were blocked in buffer $(0.1 \mathrm{M}$ Tris, $0.15 \mathrm{M} \mathrm{NaCl}, \mathrm{pH} 7.5)$ containing $10 \%$ sheep serum for lhour at RT, then incubated with an alkaline phosphatase-conjugated anti-digoxigenin $\mathrm{Ab}$ (Roche) diluted 1:5000 in the blocking buffer at $4^{\circ} \mathrm{C}$ overnight. After subsequent washes, sections were developed with NBT/5-bromo-4-chloro-3-indolyl phosphate (Roche), dried in air, mounted and examined under light microscopy.

\section{Measurements from urine and serum}

For determination of urinary albumin excretion, mice were placed individually in metabolic cages with free access to chow and 10\% liquid diet (Glucerna, Abbot Laboratories). Urine was collected for $24 \mathrm{~h}$ and albuminuria was measured using a mouse albumin ELISA kit (Bethyl Laboratories). The dilution of sample urine was adjusted to place the albumin concentrations within the linear range of the ELISA assay. Blood was collected by cardiac puncture. Serum 1,25-dihydroxyvitamin D levels were measured by the commercial ELISA kit (Immunodiagnostic System, UK). Serum 
calcium levels were measured using calcein as a calcium indicator relative to calcium standards on a Hitachi F-2500 fluorescence spectrometer. 


\section{RESULTS}

\section{Progression of DN and Altered Gene Expression in OVE26 Diabetic Mice}

In OVE26 mice diabetes begins within a few days of birth indicated by high blood glucose. Blood glucose climbs up to 2 months of age and then drops gradually thereafter $(825 \pm 37,760 \pm 36,710 \pm 41$ at 2,4 and 8 months of age, respectively $\mathrm{P}>0.05$ versus FVB). Figure 10A shows that albuminuria in the female OVE26 mice used in this study became much worse with age, averaging 800 ug per day at 2 months, climbing to 10,000 ug by 4 months and averaging over 100,000 ug at 8 months. At all ages non-diabetic mice averaged less than $250 u g$ per day.

Kidney RNA was made from OVE26 mice and control FVB mice at 2,4 and 8 months of age ( $n \geq 6$ per group). Gene expression profiles were determined on Affymetrix MG-430 2.0 arrays and analyzed using SAM 3.0 [78] with a minimal false discovery rate of $\mathrm{P}<0.05$. The number of genes altered in expression by diabetes increased (Figure 10B) from 348 genes at 2 months to 6172 genes at 8 months.

To identify genes and pathways that changed as a function of the duration of diabetes we ran a two-way ANOVA (Partek Genomic Suite) using age and diabetes as factors. This analysis combined the control and diabetic data at all ages and found 380 genes significantly altered by both age and diabetes. This gene set was then uploaded to the online database Ingenuity. Figure 11 shows the 10 most significant biological functions identified by Ingenuity. Three of the top five biological functions and/or diseases are directly related to inflammation. The number of inflammatory response genes (identified by Ingenuity data base program) up-regulated by diabetes (Figure 12) 
increased with age more than the overall change in gene expression. Some of the specific inflammatory response pathways upregulated are shown in Table 1. Of all pathways for all functions Ingenuity identified leucocyte extravasation and $\mathrm{NfkappaB}$ as the two most significant pathways at 8 months of age. Specific inflammatory genes elevated over 1.5 fold at 8 month diabetic kidney are shown in Table 2, arranged by category.

$\underline{\text { Inflammatory Genes Expressed in Diabetic Mouse Kidney }}$

Complement component 3 (C3):

C3 was the only inflammatory response gene elevated at 2 months of age. C3 was increased two-fold (Figure 13A) at 2 months and this progressed to almost 9-fold at 8 months. Within the diabetic 8 month group there was positive correlation of 0.82 $(\mathrm{P}<0.05)$ between albuminuria and C3 signal intensity $(\mathrm{P}<0.05)$. Quantitative RT-PCR validated the $\mathrm{C} 3$ array results (Figure $13 \mathrm{~B}$ and $\mathrm{C}$ ). $\mathrm{C} 3$ immunohistochemistry staining was increased, primarily in tubules with excessive albumin accumulation (Figure 13D-F). No C3 or albumin staining was seen in FVB tubules (Figure 13G-I). Since tubular C3 can come from leakage through the glomerulus or from expression within the tubule, we assessed C3 gene expression by in situ hybridization (Figure 13J-L). Only minor staining was present in 8 month FVB mice (Figure 13J) but hybridization to 8 month diabetic kidney labeled most tubules and strongly labeled some tubules (Figure 13L). The sense probe did not hybridize to any tissue (not shown). To determine if there was 
a relation between albumin accumulation and $\mathrm{C} 3 \mathrm{mRNA}$, serial sections were stained for albumin by immunofluorescence and for C3 mRNA. As shown in Figures 13L and $13 \mathrm{M}$ the tubule with the highest level of $\mathrm{C} 3$ hybridization had the strongest accumulation of albumin.

VCAM1:

VCAM1 promotes the adhesion of infiltrating cells. VCAM1 mRNA was elevated more than 4 fold at 8 months of age but not at earlier ages (Figure 14A). Pearson correlation analysis of VCAM1 signal intensity versus albumin excretion (Figure 14B) demonstrated a correlation of $0.93(\mathrm{P}<0.001)$ within the group of 8 month diabetic mice. Antibody staining (Figure 14C,D) showed that VCAM1 expression was elevated in a fraction of the diabetic tubule population, but unlike C3 staining, the positive stained VCAM1 tubules did not stain for albumin (Figure 14E,F). Since VCAM1 is a membrane bound protein it is unlikely that glomerular leakage of VCAMI contributed to tubular staining, unlike serum proteins such as albumin and C3.

CD44:

CD44 is an inflammatory response, membrane bound protein with multiple functions including regulation of VCAM1 expression [79] and promotion of macrophage infiltration. Compared to FVB control, the average microarray signal was increased 8.9 fold in OVE26 kidney at 8 months of age (Figure 15A). Pearson correlation analysis on 
expression of CD44 versus albumin excretion (Figure 15B) indicated a highly significant correlation (coefficient $=0.982, \mathrm{P}<0.0005$ ). Immunohistochemistry (Figure $15 \mathrm{C}-\mathrm{F}$ ) confirmed the microarray results and showed that increased staining was in tubular epithelial cells of OVE26 mice, as was seen for C3 and VCAM1. However, CD44 staining was more common and many CD44 stained tubules were partially or grossly dilated (Figure 15E) Age-matched controls had weak staining (Figure 15C). Also, diabetic kidneys with lower urinary albumin (Figure 15D) had weaker staining than those with higher urinary albumin (Figure 15E,F). And, as was observed for C3 staining, strong CD44 staining was associated with albumin accumulation (Figure 15G,H).

\section{Macrophage infiltration:}

The up-regulated genes described so far are implicated in inflammatory cell infiltration such as macrophages. Therefore we examined microarray results for the macrophage marker CD68 (Figure 16A). Elevated diabetic expression of CD68 was evident only at 8 months of age. Also there was a clear correlation (Figure 16B) between albuminuria and expression of CD68 in 8 month diabetic mice (correlation coefficient $=0.98, \mathrm{P}<0.0005$ ). To assess whether there was a physical association between macrophage and albumin accumulation we double stained kidneys with F4/80 macrophage antibody and antibody to mouse albumin (Figure 16C, D). Macrophages were found in diabetic kidney but rarely in control kidney. In this example the macrophages were in close proximity to tubules that had accumulated albumin, though this was not always the case. 
Relative localization of inflammatory gene products:

Individual staining for $\mathrm{C} 3, \mathrm{CD} 44$ and VCAM1 gave the impression that the prevalence of tubules staining for each protein was different. To test this directly, we triple stained OVE26 sections for each of these markers (Figure 17). Consistent with separate staining results (Figure 17) the most prevalent staining was for CD44 and in some cases the same tubules stained for C3. VCAM1 stained tubules did not stain for CD44 or C3 and VCAM1 was not induced in dilated tubules (Figures 14 and 17). Based on thickness, brush border and megalin staining (not shown), most stained tubules were proximal tubules.

\section{Expression of CYP27B1 and Vitamin D Level in OVE26 Diabetic Kidney}

Renal inflammation induces CYP27B1 [69], the rate limiting enzyme catalyzing synthesis of active vitamin $\mathrm{D}$ (1,25-dihydroxy vitamin $\mathrm{D})$. In 2 and 4 month old OVE26 mice CYP27B1 mRNA level was increased 3 to 4 fold above control mice and this rose to 9 fold at 8 months age (Figure 18A). Unlike other inflammatory proteins, its mRNA expression did not correlate with albuminuria (data not shown). Immunohistochemistry confirmed the diabetes induced elevation of CYP27B1 expression (Figures 18C,D). As reported [80] CYP27B1 protein was present in most kidney cells. Given both altered mRNA and protein expression of this enzyme in diabetic mice, we 
measured serum level of its hydroxylation product 1,25-dihydroxy vitamin D. Serum 1,25-dihydroxy vitamin D was increased 2.4 fold in diabetic mice (Figure 18B). Since vitamin $\mathrm{D}$ is a regulator of in vivo calcium homeostasis, we also measured serum $\mathrm{Ca}^{2+}$ levels and found that serum $\mathrm{Ca}^{2+}$ levels were reduced in diabetic mice $(8.6 \pm 0.3 \mathrm{mg} / \mathrm{dl}$ for OVE26 and $9.8 \pm 0.1 \mathrm{mg} / \mathrm{dl}$ for $\mathrm{FVB}, \mathrm{P}<0.01, \mathrm{n}=5$ ) (Figure 18E). A correction analysis were performed to adjust the effect of reduced serum albumin level on total serum calcium measurement in OVE26 mice and the adjusted results showed similar reduction of serum calcium levels in diabetic mice. (data not shown)

\section{Expression of Fat Metabolism Genes in OVE26 Diabetic Kidneys}

We found one prior paper that examined changes in gene expression in OVE26 kidney [81]. That study used syber green rtPCR to identify 2 to 3 fold changes in expression of 14 genes of fat metabolism or their transcriptional regulatory genes SREBPs 1 and 2 and PPARs $\alpha$ and $\zeta$. They proposed that increased OVE26 renal fatty acid and cholesterol content were due to combined reductions in transcription of mRNA for fatty acid oxidation genes and cholesterol efflux genes plus increased transcription of mRNA of fatty acid and cholesterol synthesis genes. In this study, using gene array, we found none of the changes previously reported for these 14 genes (Table 3). Five genes for fatty acid synthesis or transcriptional regulators were reported to be up-regulated in the previous study, but we did not find these genes up-regulated. In fact three were down-regulated. Two genes of fatty acid synthesis and two genes of cholesterol efflux 
were previously reported to be increased but all were unchanged in the present study. Two genes of cholesterol synthesis were reported to be up-regulated, but we found them to be essentially unchanged. These results at 4 months of age were consistent with our results at 2 months and 8 months of age (data not shown).

As shown in figure 19, the reduction in expression found for FASN was confirmed by Taqman RT PCR (fold change $0.43+0.07$, respectively, $\mathrm{P}<0.05$ by $\mathrm{t}$-test). The most notable aspect of the current results is that the 4 genes that were significantly down-regulated are all induced by nuclear receptor SREBF1 [82,83]. (Figure 20) 


\section{DISCUSSION}

This study provides the initial microarray analysis of the OVE26 kidney and thus the first study of gene expression changes of whole kidney during the development from mild to very severe diabetic albuminuria. Future studies will assess changes in gene expression of isolated glomeruli and podocytes. In OVE26 mice the daily albumin excretion progressed from $1 \mathrm{mg}$ at 2 months to profound albuminuria of almost $100 \mathrm{mg}$ at 8 months. The progression of albuminuria was paralleled by a significant alteration in gene expression of over 6000 kidney genes. Ingenuity pathway analysis indicated that the inflammatory response pathway was the most overrepresented biological pathway, and expression in this pathway increased almost exponentially with the progression of albuminuria. Inflammatory genes of the complement pathway that have not been shown to be up-regulated in other animal models of diabetes were greatly elevated in OVE26 kidneys.

\section{Albuminuria, NF-kappa B and The Inflammatory Gene Response}

Human renal gene expression profiles have also linked inflammatory pathways to DN $[76,84]$. In animal models of DN, some papers reported up-regulation of several inflammatory genes [85] but others did not [86]. We proposed that the stimulus for the increase in 300 inflammatory response genes in older OVE26 kidneys was due to their extreme albuminuria, which by 8 months was more than 500 fold higher 
than in non-diabetic mice. This is in contrast to a 34 -fold or lower increase in albuminuria in other diabetic models $[5,87,88]$. In fact the OVE26 inflammatory response at 4 months of age, when albuminuria was induced only 30 fold, was not especially prominent and included less than 25 genes. The association between severe albuminuria and gene expression does not prove that protein leakage caused the observed changes in inflammatory gene expression. However the role of albumin leakage is supported by the fact that there was a very strong correlation to albuminuria between individual diabetic mice of the same age and by the co-localization of albumin staining and staining for several inflammatory genes.

The pro-inflammatory role of proteinuria is consistent with numerous in vitro studies where protein exposure of tubule epithelial cells activated Nf-kappa B and induced inflammation (reviewed in [89]). Ingenuity pathway analysis (Table 1) showed that the NF-kappa B pathway was significantly upregulated in 8 month diabetic kidneys. Schmid et al [76] proposed that the NF-kappa B promoter module NFKB_IRFF_01 was a marker of advanced human DN since they found induction of 8 of 9 genes controlled by this promoter module in progressive human DN samples. Of the 8 genes identified by Schmid et al, we found 6 (VCAM1, CXCL10, CCL5, HLA-B, EDN1 and B2M) were upregulated in our oldest age diabetic group but none in our younger age diabetic groups. Analagous to the activation of the NFKB_IRFF_01 module in advanced human DN, our results suggest that progressive DN develops between 4 and 8 months of age in OVE26 mice.

\section{Complement Component C3}


C3 mRNA was the only inflammatory response gene up-regulated in 2 month old diabetic mice and the expression level increased markedly with age and albuminuria. C3 over-expression was confirmed by RT-PCR and in situ hybridization. In vitro studies have demonstrated that exposure of cultured tubular cells to serum proteins increases $\mathrm{C} 3$ expression [90]. Urinary C3 induction has been reported in human diabetic nephropathies [91] but not to our knowledge in tubules of any other diabetic animal models. Again, this may be because other diabetic models have less proteinuria than OVE26 mice. In situ results showed that $\mathrm{C} 3$ mRNA was increased in most OVE26 tubules and serial section analysis showed that the strongest $\mathrm{C} 3$ reaction co-localized with the most intense albumin immunostaining, providing further evidence that C3 induction in diabetic mouse tubular cells is secondary to excessive albumin leakage into the proximal tubules.

C3 can produce direct tissue damage and promote inflammation. Renal accumulation of $\mathrm{C} 3$ has been shown to be a major component of the pathology of several non-diabetic nephropathies $[92,93]$ and inhibition of C3 has been shown to be highly beneficial to mouse models of nephropathy $[93,94]$ though this has not been tested in diabetic models. Chronic activation of $\mathrm{C} 3$ promotes further inflammation and activation of $\mathrm{C} 3$ expression in tubules of young OVE26 mice may have contributed to the further stimulation of additional inflammatory response genes. Since OVE26 mice are the first diabetic model to demonstrate $\mathrm{C} 3$ accumulation in the kidney, they provide the first opportunity to examine the importance of $\mathrm{C} 3$ in the progression of DN. It is notable that the background strain for OVE26 mice, FVB is deficient in C5, which prevents formation 
of the membrane attack complex. Complement mediated damage in FVB mice is largely limited to cleavage products of $\mathrm{C} 3$. Crossbreeding to add a functional $\mathrm{C} 5$ gene should result in more severe DN more closely mimicking human DN.

\section{Adhesion molecules and macrophage infiltration}

Two inflammatory response genes that were up-regulated more than 4-fold at 8 months of age but not at earlier ages were VCAM1 and CD44. Among other activities, both proteins increase adhesion of infiltrating cells. In normal control tissue VCAM-1 was present on some (but not all) parietal epithelial cells lining Bowman's capsule, additional presence of VCAM-1 on proximal tubular cells was observed in clinical biopsy specimens from patients with diabetic nephropathy. Tubule VCAM1 expression is induced by the NF-kappa B transcriptional pathway $[76,95]$. In diabetic patients, induction of VCAM1 expression may serve as a marker for progressive DN with 2.5 fold higher expression in advanced DN samples compared to samples from patients with early DN or minimal change disease [76]. We did not find reports of VCAM1 induction in other animal models of DN. CD44 is induced in kidneys injured by ischemia [96] or autoimmunity [97] and CD44 contributes to renal neutrophil and macrophage infiltration [98]. Induction of CD44 has not been reported in diabetic kidneys and CD44 is not induced in proximal tubule cell lines by high glucose [99]. 


\section{Expression of both VCAM1 and CD44 genes displayed correlation}

coefficients greater than 0.9 versus the level of albuminuria. As shown by immunohistochemistry both proteins localized to tubule epithelial cells within what appeared to be proximal tubules, as indicated by the thickness of the tubule wall and the presence of a brush border and megalin. This localization is consistent with prior reports for CD44 [97] and VCAM1 [95]. However, despite the fact that both CD44 and VCAM1 were induced in proximal tubule cells at the same age, 8 months, they were induced in different tubules. Several characteristics differentiated CD44 and VCAM1 positive tubules. CD44 cells were much more abundant than VCAM1 cells. CD44 stained tubules were often positive for albumin and C3 staining and CD44 positive tubules were often grossly dilated. In contrast VCAM1 positive tubules did not stain for albumin or $\mathrm{C} 3$ and they never exhibited grossly dilated lumen. We recently reported [100] that tubules that accumulate albumin have a damaged brush border and abnormal epithelial cell protrusions extending into the tubular lumen, indicating that albumin accumulation produces significant proximal tubule cell injury. The greater damage, evident in CD44 positive cells as suggested by dilation and albumin accumulation, suggests that CD44 and VCAM1 expression are associated with different stages of tubule pathology.

Macrophage infiltration is commonly observed in diabetic and non-diabetic renal disease and is widely considered to contribute to chronic renal damage. CD68 is a macrophage protein used as a marker for macrophage infiltration. In OVE26 kidneys, CD68 expression followed the common inflammatory response pattern of not increasing 
significantly until 8 months of age, at which time it was elevated 5.6-fold. A search of the Ingenuity database for the term macrophage returned six genes, of which 5 were significantly increased in the diabetic 8 month dataset. It is likely that the late increase in the renal leukocyte extravasation pathway genes (Table 2) such as CD44 and VCAM1 paralleled the time course of macrophage infiltration and CD68 gene expression.

\section{$\underline{\text { CYP27B1 and serum vitamin D levels }}$}

Vitamin D is now recognized as a modulator of the immune system [101]. There are also findings that low vitamin D levels are related to increased inflammation in human renal diseases [69]. In mouse models of Type 1 and 2 diabetes, supplementary vitamin $D$ reduces diabetic nephropathy and renal inflammation [73]. In nephropathy patients [69] there is a significant correlation between expression of CYP27B1, the rate limiting enzyme for formation of active vitamin D and renal inflammation. Elevated serum vitamin D and CYP27B1 expression have been reported in the dbdb Type 2 model of DN [73].

In OVE26 mice CYP27B1was the third most upregulated gene at 2 months of age. At this age OVE26 mice have already attained extremely high blood glucose levels [16] but they do not exhibit renal inflammation or significant albuminuria. This suggests that severe hyperglycemia is sufficient to induce the CYP27B1 gene. Alternatively, low serum calcium in OVE26 mice, is also known to stimulate CYP27B1 expression [102]. The fact that CYP27B1 expression increased another 3-fold at 8 
months of age, when albuminuria and inflammation increased indicates that these factors produce further induction of gene expression. Presumably as a result of increased expression of CYP27B1 protein, serum levels of vitamin D were two fold elevated in 8 month old OVE26 mice. While this may have partially ameliorated renal and systemic inflammation it was clearly not sufficient to prevent the inflammatory response of the OVE26 kidney.

\section{Fat metabolism gene expression}

This analysis of diabetes effects on fat metabolism genes revealed significant reductions in expression of 4 genes of fatty acid or cholesterol synthesis, SREBF 1, FASN ACACA and HMGCR. SREBF1 is a transcription factor that induces its own expression as well as expression of many enzymes of fat synthesis including HMGCR, FASN and ACACA. Further analysis showed many other SREBF1 regulated genes were reduced at 4 and/or 8 months of age (Figure 20) and UCP2 and SLC2A2 genes that are repressed by SREBF1 were significantly increased. Thus the reduction in SREBF1 plays a large role in these changes of gene expression. The SREBF1 gene is responsive to insulin, therefore the virtual absence of insulin in OVE26 mice can explain the decline in SREBF1 expression.

Procotor et al [81] proposed that diabetes induces coordinate changes in mRNA expression for genes integral to fat metabolism resulting in increased fatty acid and cholesterol content in diabetic kidney. This then accelerates nephropathy. We 
have also observed elevated renal cholesterol content in OVE26 kidney [103] however in the current study we did not confirm the changes reported for expression of 14 genes of fatty metabolism in OVE26 kidneys. In fact where expression changes were observed they were in the opposite direction to what was reported by Proctor et al. Our findings do not support the previous hypothesis that diabetes induced changes in renal nuclear transcription factors for genes of fatty acid metabolism promotes DN. The reliability of our results are supported by the fact that they were consistent at multiple ages and they were confirmed for the FASN gene by probe based rtPCR. They are also supported by comparison of our data to a very recent publication [104] that found elevations in the mRNA levels for 3 genes in OVE26 kidney cortex of 7 month old mice by rtPCR. That studied found increases for serpine1, TGF $\beta 1$ and TGF $\beta$ induced mRNAs of $4.3,1.9$ and 1.4 fold, respectively, while we found by gene array analysis similar increases of $2.8,1.7$ and 1.8 fold for the same genes at 8 months of age.

\section{Summary}

Microarray expression analysis shows that OVE26 mice develop features of advanced DN between 4 and 8 months of age. Overall inflammatory gene expression increases dramatically in association with increasing albuminuria and activation of NF-kappa B dependent pathways. As shown in Figure 21, OVE26 mice display elevated expression of $\mathrm{C} 3$ at an early stage of diabetes, which is possibly induced by the moderate protein leakage. When OVE26 mice aged and entered late stage of diabetes, 
they exhibited excessive protein leakage. At this stage, C3 expression elevation may be reinforced by increased pro-inflammatory cytokines expression (indicated in table 2) and induced by accumulated albumin in tubules. Increased urinary albumin level was associated with elevated expression of adhesion molecules, VCAM1 and CD44. The Nf-kB inflammatory pathway was up-regulated in late stage diabetes and positively regulated VCAM-1 expression [76,95]. The expression of these genes (C3, VCAM-1, CD44) appears to be regulated differentially in different OVE26 tubules depending on the level of pathology in each nephron. These proteins have been shown to play a role in kidney injury in non-diabetic animal models of nephropathy but that have not been shown to be elevated in other models of diabetic kidney disease. Figure 21 provides a visual scheme for this proposed pathway for progression of diabetic nephropathy. Based on our immunohistochemistry results, increased macrophage infiltration was also related to tubular albumin leakage. Expression of CYP27B1, the regulator of active vitamin D synthesis was elevated early in diabetes but increased further when inflammation peaked at 8 months of age. 
Table 1. Inflammatory pathways activated by diabetes based on ingenuity analysis.

Columns show the number of genes altered with FDR $<5 \%$ by SAM at each age.

\begin{tabular}{|l|l|l|l|l|}
\hline Pathway name (number of genes in pathway) & $\mathbf{2 m}$ & $\mathbf{4 m}$ & $\mathbf{8 m}$ & P value at 8m \\
\hline Leukocyte Extravasation signaling (191 genes) & 0 & 16 & 80 & $4.99 \mathrm{E}-14$ \\
\hline NF-kB Signaling (143 genes) & 3 & 0 & 61 & $7.65 \mathrm{E}-11$ \\
\hline IL-4 signaling (68 genes) & 4 & 7 & 33 & $1.24 \mathrm{E}-08$ \\
\hline IL-2 signaling (53 genes) & 0 & 3 & 24 & $1.71 \mathrm{E}-05$ \\
\hline IL-6 signaling (91 genes) & 0 & 3 & 29 & $3.05 \mathrm{E}-03$ \\
\hline Complement system (36 genes) & 2 & 3 & 12 & $7.85 \mathrm{E}-03$ \\
\hline
\end{tabular}


Table 2. Pro-inflammatory genes up-regulated at least 1.5 fold in 8 month diabetic

kidney

\begin{tabular}{|c|c|c|c|}
\hline Gene Title & Gene Symbol & $p$-value & fold change \\
\hline \multicolumn{4}{|l|}{ TNF \& receptor } \\
\hline tumor necrosis factor receptor superfamily, member $1 \mathrm{~b}$ & Tnfrsf1b & $2.32 \mathrm{E}-04$ & 1.89 \\
\hline tumor necrosis factor receptor superfamily, member $12 a$ & Tnfrsf12a & $2.35 \mathrm{E}-03$ & 2.53 \\
\hline tumor necrosis factor, alpha-induced protein 3 & Tnfaip3 & $2.31 \mathrm{E}-03$ & 2.00 \\
\hline tumor necrosis factor (ligand) superfamily, member 13b & Tnfsf13b & $2.36 \mathrm{E}-02$ & 1.70 \\
\hline \multicolumn{4}{|l|}{ Interleukin family } \\
\hline interleukin 1 family, member 6 & 11176 & $9.19 \mathrm{E}-03$ & 2.58 \\
\hline \multicolumn{4}{|l|}{ TLRs } \\
\hline toll-like receptor 1 & Tr1 & $1.94 \mathrm{E}-03$ & 1.86 \\
\hline toll-like receptor 13 & Tr13 & $7.06 \mathrm{E}-03$ & 1.60 \\
\hline toll-like receptor 2 & $\pi r^{2}$ & $2.13 \mathrm{E}-02$ & 1.99 \\
\hline toll-like receptor 4 & Tr4 & $5.05 \mathrm{E}-02$ & 1.64 \\
\hline \multicolumn{4}{|l|}{ chemokine } \\
\hline chemokine (C-C motif) ligand 7 & $\mathrm{Ccl} 7$ & $2.00 \mathrm{E}-03$ & 1.52 \\
\hline chemokine (C-C motif) ligand 12 & $\mathrm{Cc} 112$ & $5.50 \mathrm{E}-03$ & 5.48 \\
\hline chemokine (C-C motif) ligand 2 & $\mathrm{Cc} / 2$ & $9.65 \mathrm{E}-03$ & 4.25 \\
\hline chemokine (C-C motif) ligand 5 & $\mathrm{Ccl5}$ & $1.49 \mathrm{E}-02$ & 3.36 \\
\hline chemokine (C-C motif) ligand 9 & $\mathrm{Cc} 19$ & $1.89 \mathrm{E}-02$ & 3.83 \\
\hline chemokine ( $\mathrm{C}-\mathrm{C}$ motif) ligand 6 & Ccl6 & $2.77 \mathrm{E}-02$ & 3.36 \\
\hline chemokine (C-C motif) ligand 8 & Ccl8 & $3.69 \mathrm{E}-02$ & 3.33 \\
\hline chemokine (C-X-C motif) ligand 11 & Cxcl11 & $2.38 \mathrm{E}-04$ & 2.99 \\
\hline chemokine (C-X-C motif) ligand 16 & Cxcl16 & $6.09 \mathrm{E}-04$ & 1.89 \\
\hline chemokine (C-X-C motif) ligand 10 & $\overline{C x c / 10}$ & $5.05 E-04$ & 3.81 \\
\hline chemokine (C-X-C motif) ligand 2 & $\mathrm{Cxcl} 2$ & $1.03 E-02$ & 3.41 \\
\hline chemokine (C-X-C motif) ligand 13 & $\mathrm{Cxc} / 13$ & $1.58 \mathrm{E}-02$ & 2.45 \\
\hline chemokine (C-X-C motif) ligand 1 & $\mathrm{Cxcl} 1$ & $1.35 \mathrm{E}-02$ & 2.65 \\
\hline \multicolumn{4}{|l|}{ Adhesion molecules } \\
\hline intercellular adhesion molecule & Icam1 & $7.21 \mathrm{E}-03$ & 2.04 \\
\hline vascular cell adhesion molecule 1 & Vcam1 & $4.98 \mathrm{E}-03$ & 4.58 \\
\hline CD44 antigen & $\mathrm{Cd} 44$ & $1.02 \mathrm{E}-02$ & 8.01 \\
\hline
\end{tabular}


Table 3. Fold change in fat metabolism mRNA expression

\begin{tabular}{|l|l|c|}
\hline $\begin{array}{l}\text { Gene } \\
\text { Symbol }\end{array}$ & $\begin{array}{l}\text { Gene metabolic } \\
\text { functions }\end{array}$ & OVE26/FVB \\
\hline SREBP1 & Fatty acid synthesis & $0.53 \pm 0.04$ \\
\hline FASN & Fatty acid synthesis & $0.49 \pm 0.05$ \\
\hline L-PK & Fatty acid synthesis & $1.12 \pm 0.03$ \\
\hline ACC & Fatty acid synthesis & $0.64 \pm 0.04$ \\
\hline PPAR-a & Fatty acid oxidation & $1.08 \pm 0.13$ \\
\hline PPAR- $\zeta$ & Fatty acid oxidation & $0.98 \pm 0.04$ \\
\hline ACO & Fatty acid oxidation & $0.91 \pm 0.08$ \\
\hline SREBP2 & Cholesterol synthesis & $0.86 \pm 0.04$ \\
\hline HMGCR & Cholesterol synthesis & $0.71 \pm 0.04$ \\
\hline ABCA1 & Cholesterol efflux & $1.02 \pm 0.15$ \\
\hline
\end{tabular}


A Estimated prevalence of diagnosed and undiagnosed diabetes in people aged 20 years or older, by age group, United States, 2007

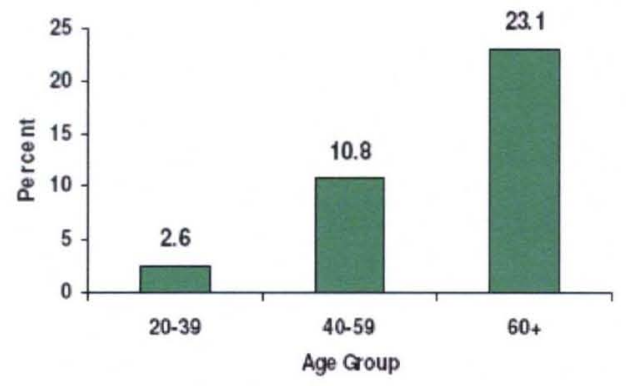

Source: 2003-2006 National Health and Nutrition Examination Survey estimates of total prevalence (both diagnosed and undiagnosed) were projected to year 2007.

\section{B Primary Causes of Kidney Failure (2005)}

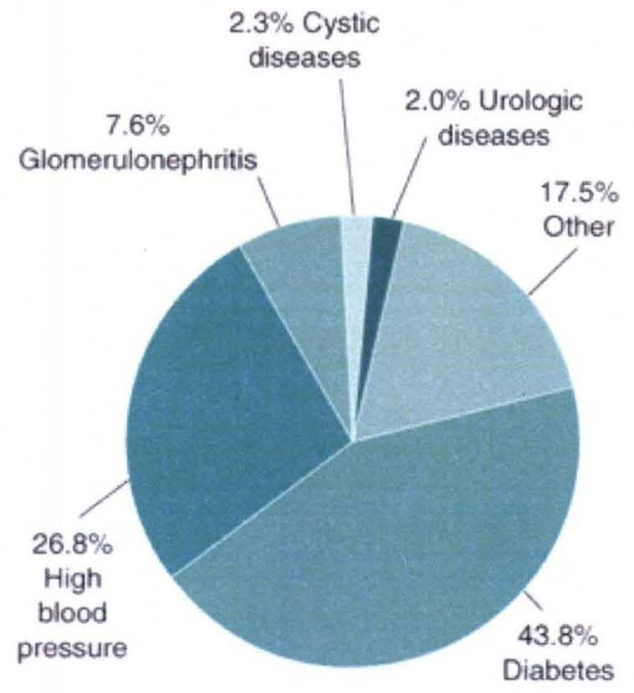


Figure 9: Diabetes Statistics. A) Estimated prevalence of diagnosed and undiagnosed diabetes in people aged 20 years or older, by age group, United States, 2007; B) Primary causes of kidney failure (2005). 

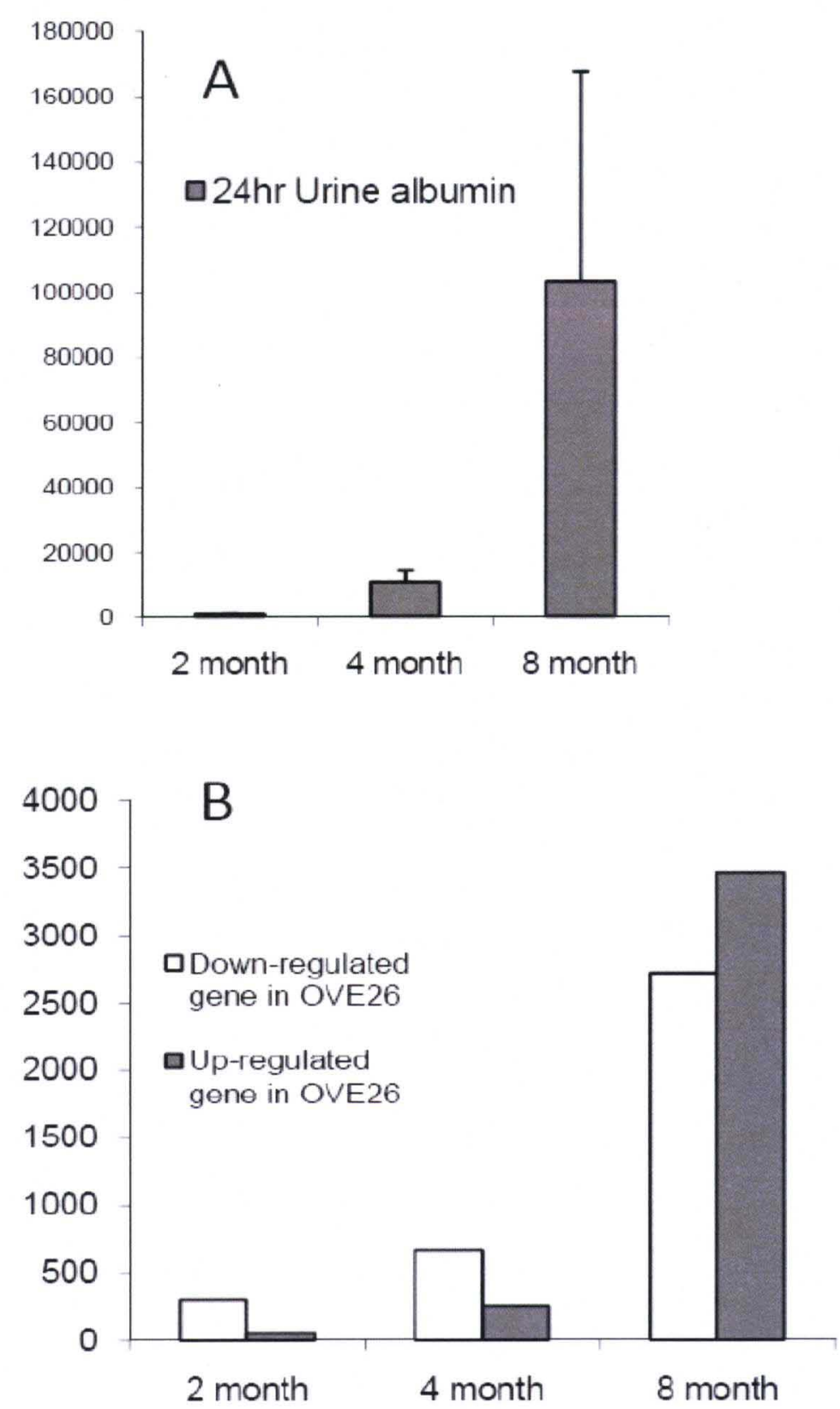
Figure 10. Developmental changes in albuminuria and gene expressions: Panel A shows the increase in $24 \mathrm{hr}$ urine albumin excretion in female OVE26 mice with age. At each age diabetic albuminuria was greater than the next youngest group $(\mathrm{P}<0.01$ by ANOVA) and greater than control mice of the same age $(\mathrm{P}<0.05$ by $\mathrm{T}$-test $) . \quad$ (Values are the means \pm SE of 6 or more mice for each age group). Panel B shows the number of genes significantly up or down-regulated in OVE26 mice at each age. Results were based on SAM adjusted FDR level of 0.05 . 
Immunological Disease

Connective Tissue Disorder's

Inflammatory Disease

Skeletal and Muscular Disorder's

Immune Response

Cellular Movement

Hematological System

Development and Function

Cell-To-Cell Signaling and Inter action

Organismal Injury and Abnormalities

Immune and Lymphatic

System Development and Function 
Figure 11: Top 10 biological functions and/or diseases altered by both age and diabetes: Three of the top five top biological functions identified by Ingenuity are related to inflammation. 


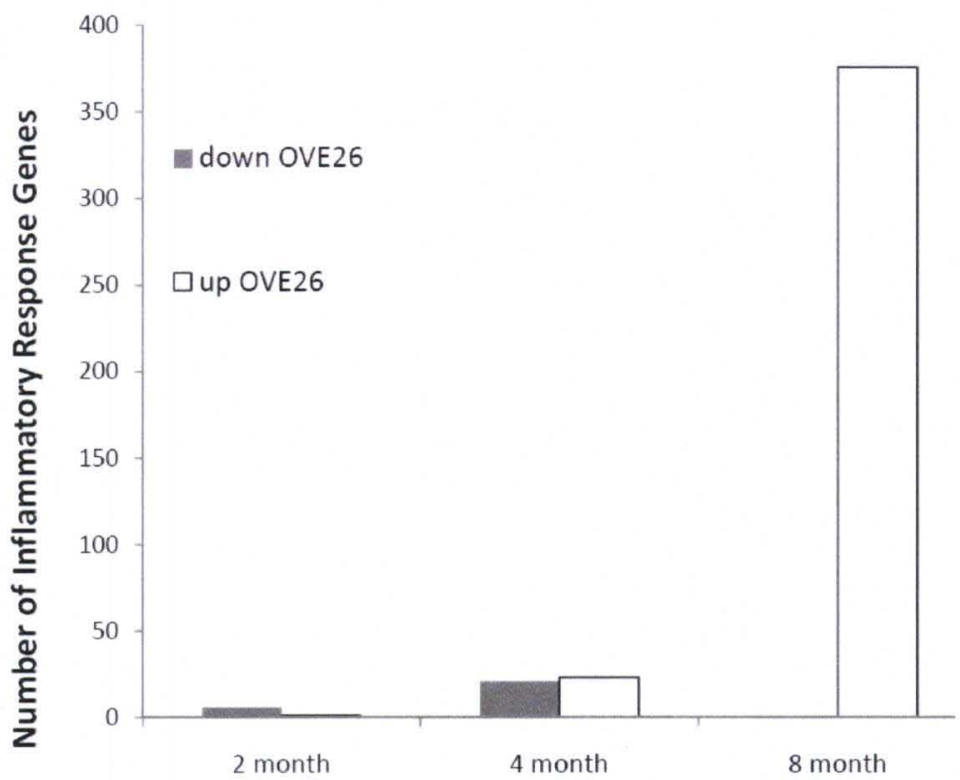


Figure 12: Expression of inflammatory response genes identified by Ingenuity online database increased by age in diabetic kidneys: Gray bar stands for down-regulated genes (OVE26 Vs FVB), white bar stands for up-regulated genes. 

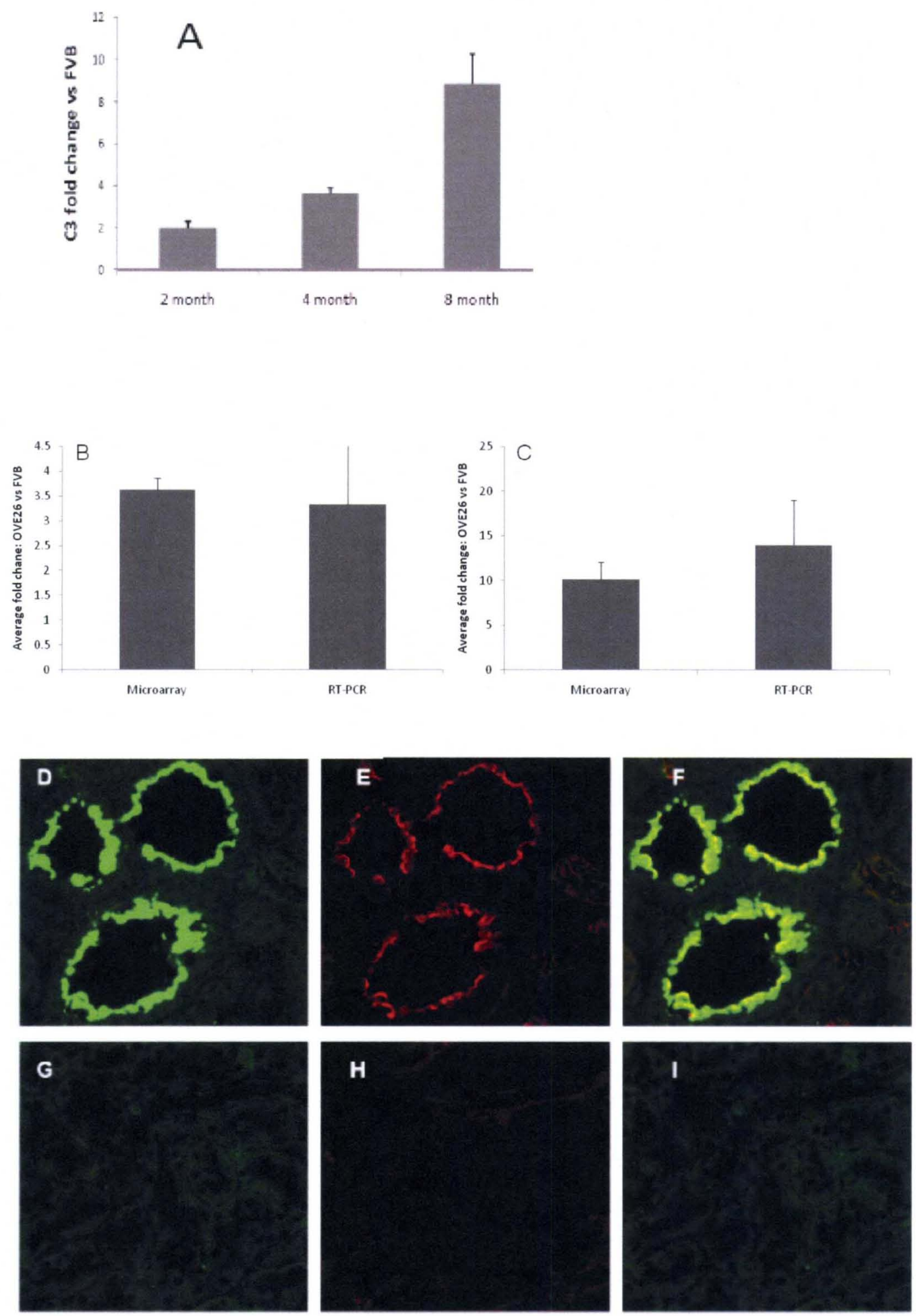

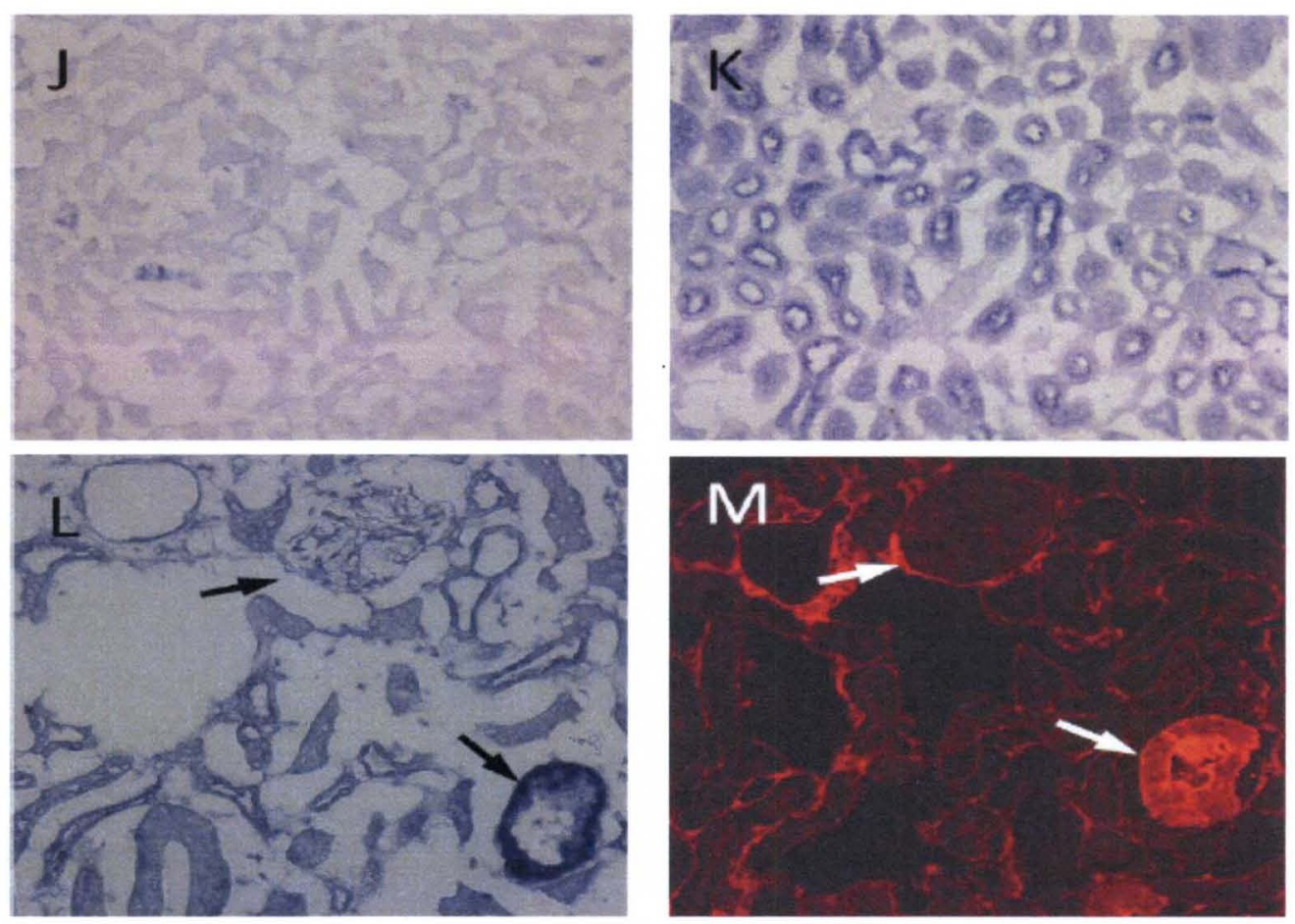


\section{Figure 13. Complement component 3 (C3) mRNA and protein are up-regulated in}

diabetic mouse kidney. A) C3 mRNA is increased in diabetic mice at all ages based on Affymetrix array results. $\quad \mathrm{Y}$ axis shows the fold change of OVE26 over FVB $(\mathrm{P}<0.002$ for each age by T-test). Microarray results were validated by real-time PCR at 4 months (B) and 8 months (C). Immunofluorescent staining of C3 on sections of (D) diabetic or (G) control kidneys. Dual labeling for albumin on the same sections is shown in Panels $\mathrm{E}$ and $\mathrm{H} . \quad$ Merged pictures of both stains are shown in panels $\mathrm{F}$ and $\mathrm{I}$ for diabetic and control kidneys, respectively. Original magnification X400. In situ hybridization shows C3 mRNA in tubular cells of diabetic mouse. J) Kidney from 8 month old control FVB mouse showed weak staining. K) Kidney from an age-matched OVE26 mouse showed positive (dark blue) staining in many tubules. Serial sections of OVE26 kidney reveal the strongest C3 hybridization (L lower arrow) in a tubule that stained strongly for albumin (M lower arrow). The upper arrows in panels $\mathrm{L}$ and $\mathrm{M}$ point to a common glomerulus used for aligning the sections. Original magnification X200. 

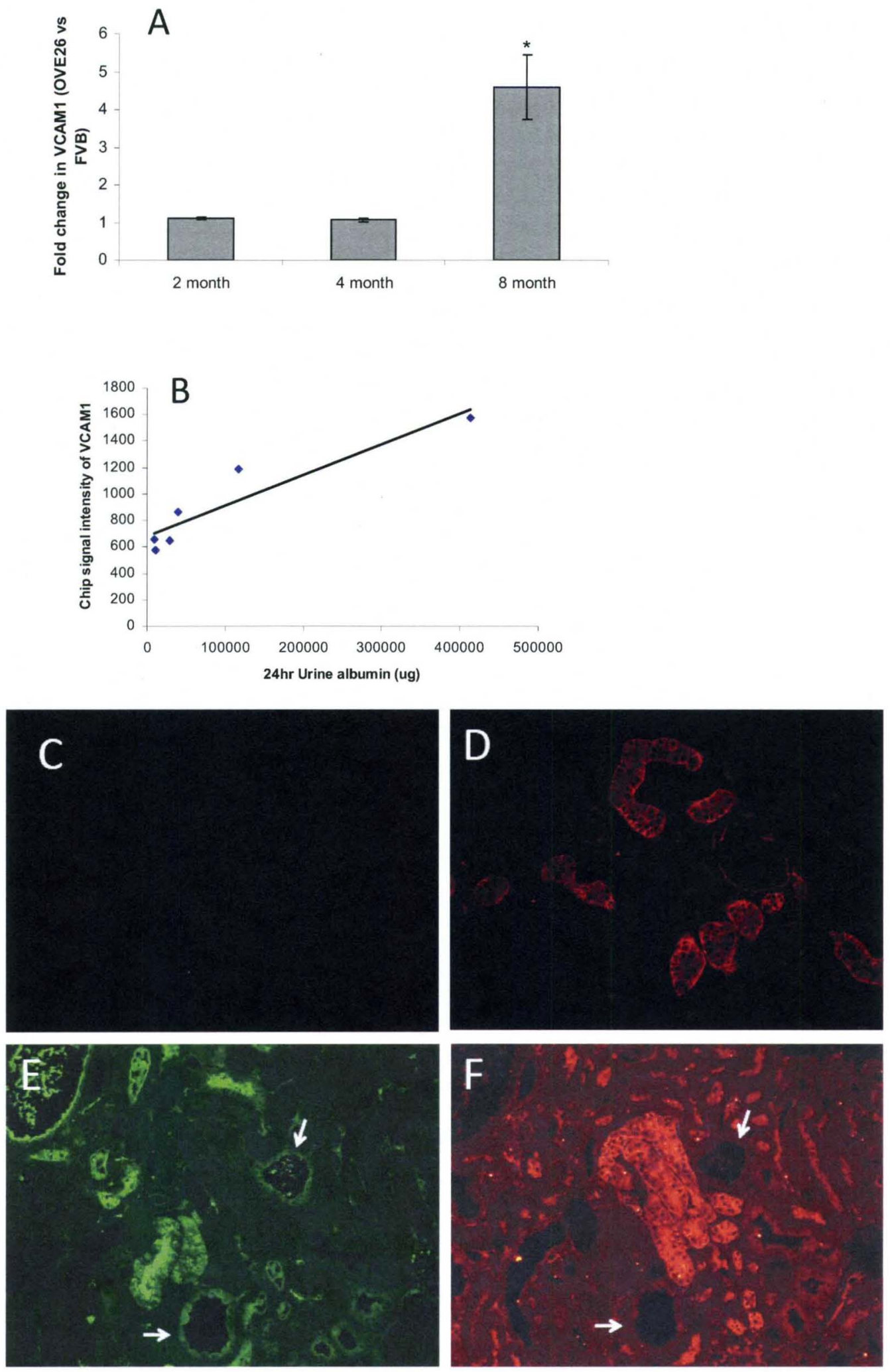
Figure 14. Increased VCAM1 expression in 8 month old diabetic kidney. A)

VCAM1 RNA expression level is up-regulated by diabetes only at 8 months of age according to microarray results. Y axis shows the fold increase of OVE26 relative to FVB. The asterisk indicates that VCAM1 elevation is significant at that age $(\mathrm{P}<0.01$, T-test). B) Pearson correlation analysis of VCAM1 gene array signal versus 24 hour urinary albumin excretion $\left(\mathrm{R}^{2}=0.933, \mathrm{P}<0.01\right)$. Immunohistochemical staining of VCAM1 on paraffin sections of C) control or D) diabetic kidney. Panels E and F show serial sections of diabetic kidney stained for albumin (green) or for VCAM1 (red). The white arrows indicate landmarks that allow rapid visual alignment of the serial sections. The staining shows that OVE26 tubules that stain strongly for VCAM1 do not stain strongly for albumin. Original magnification X200 

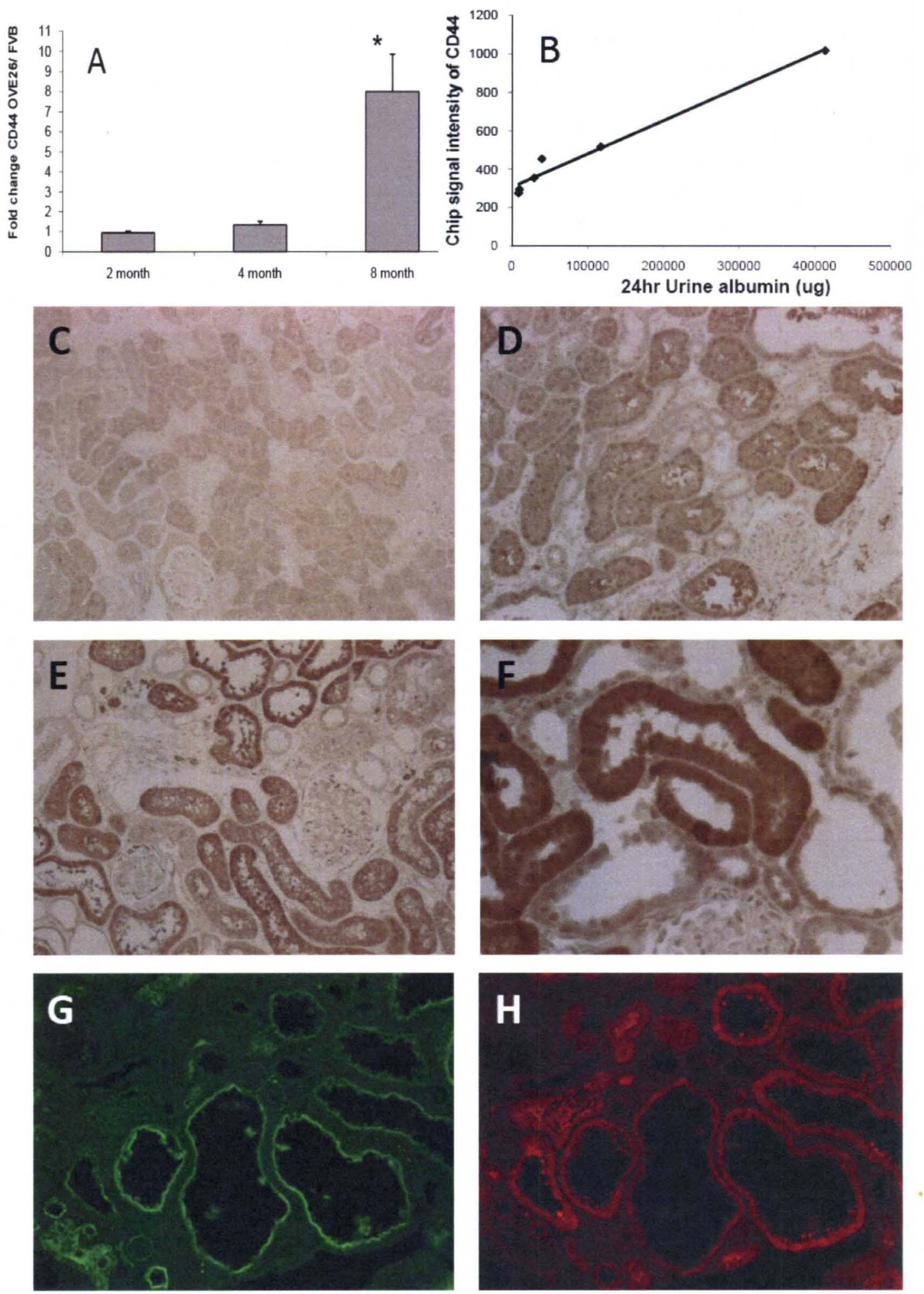
Figure 15. Increased CD44 expression in 8 month old diabetic kidney. A)

Microarray results show that CD44 mRNA levels are up-regulated significantly only at 8 months of age. The asterisk indicates that the elevation of gene expression level is significant $(\mathrm{P}<0.0001, \mathrm{t}$-test $)$ between control and diabetic 8 month old mice. B) Correlation analysis of CD44 expression versus albuminuria in diabetic 8 month mice (Pearson correlation coefficient $=0.982, \mathrm{P}<0.0005$ ). Immunohistochemical staining for CD44 on sections of FVB (C) or diabetic kidney with moderate (D) or severe (E,F) albuminuria. Panels G (albumin) and H (CD44) show that many tubules, especially dilated tubules, stain for both albumin and CD44. All original magnification X200 except F, X400 

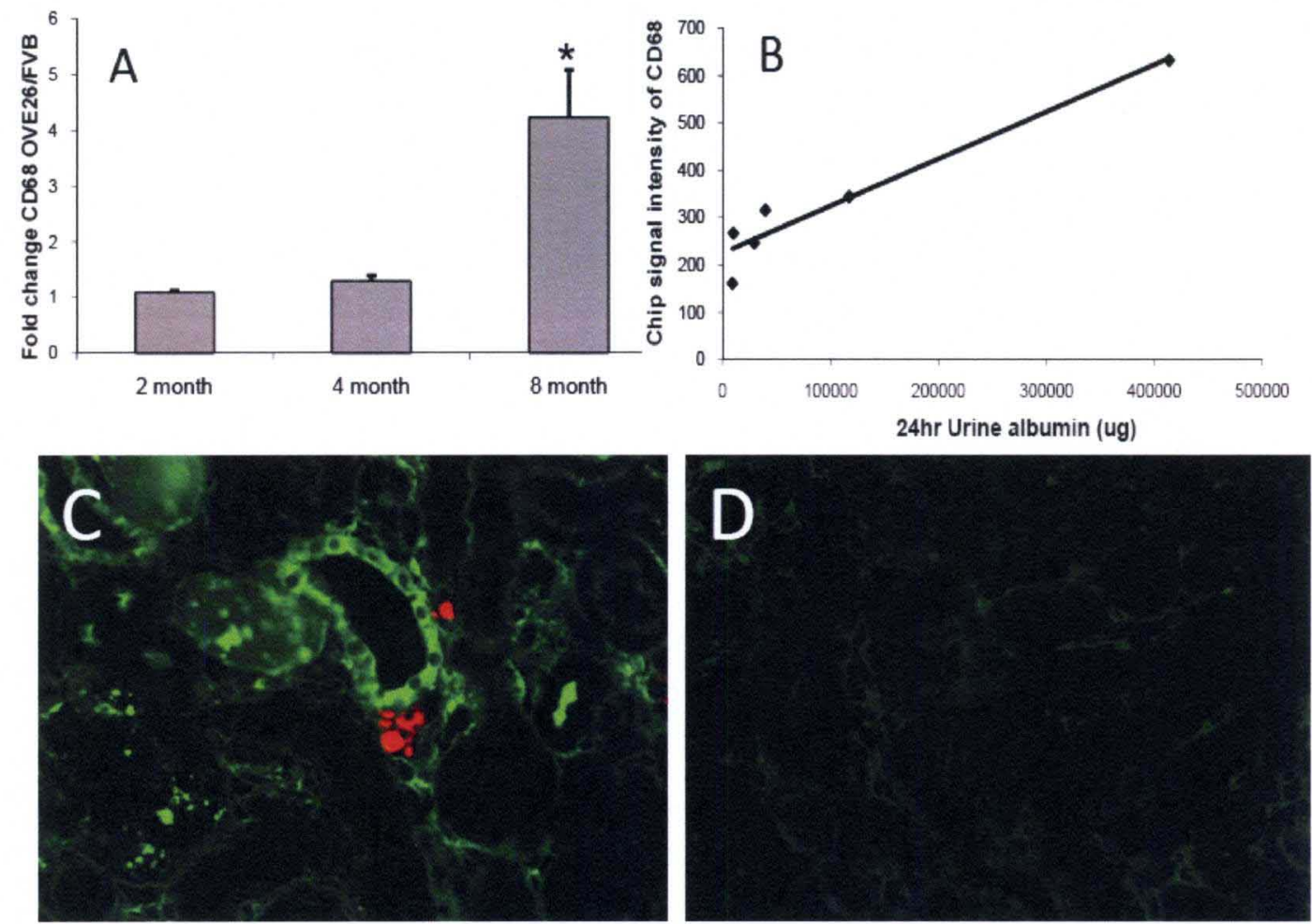
Figure 16. Increased CD68 expression and macrophage infiltration in 8 month

diabetic kidney. A) Gene array results show that the macrophage marker CD68 mRNA increased significantly in 8 month diabetic kidney. Asterisk indicates that the elevation of gene expression level is significant $(\mathrm{P}<0.01$, t-test) at that age. B) Correlation analysis of CD68 expression and 24 hour urine albumin excretion $\left(\mathrm{R}^{2}=0.965, \mathrm{P}<0.005\right)$. C) Immunofluorescent staining of macrophage with F4/80 antibody (red) on tubulointerstitial area of 8 month diabetic kidney section merged with albumin staining on the same section (green). D) FVB sections presented no staining of macrophage. Original magnification $\mathrm{X} 400$. 


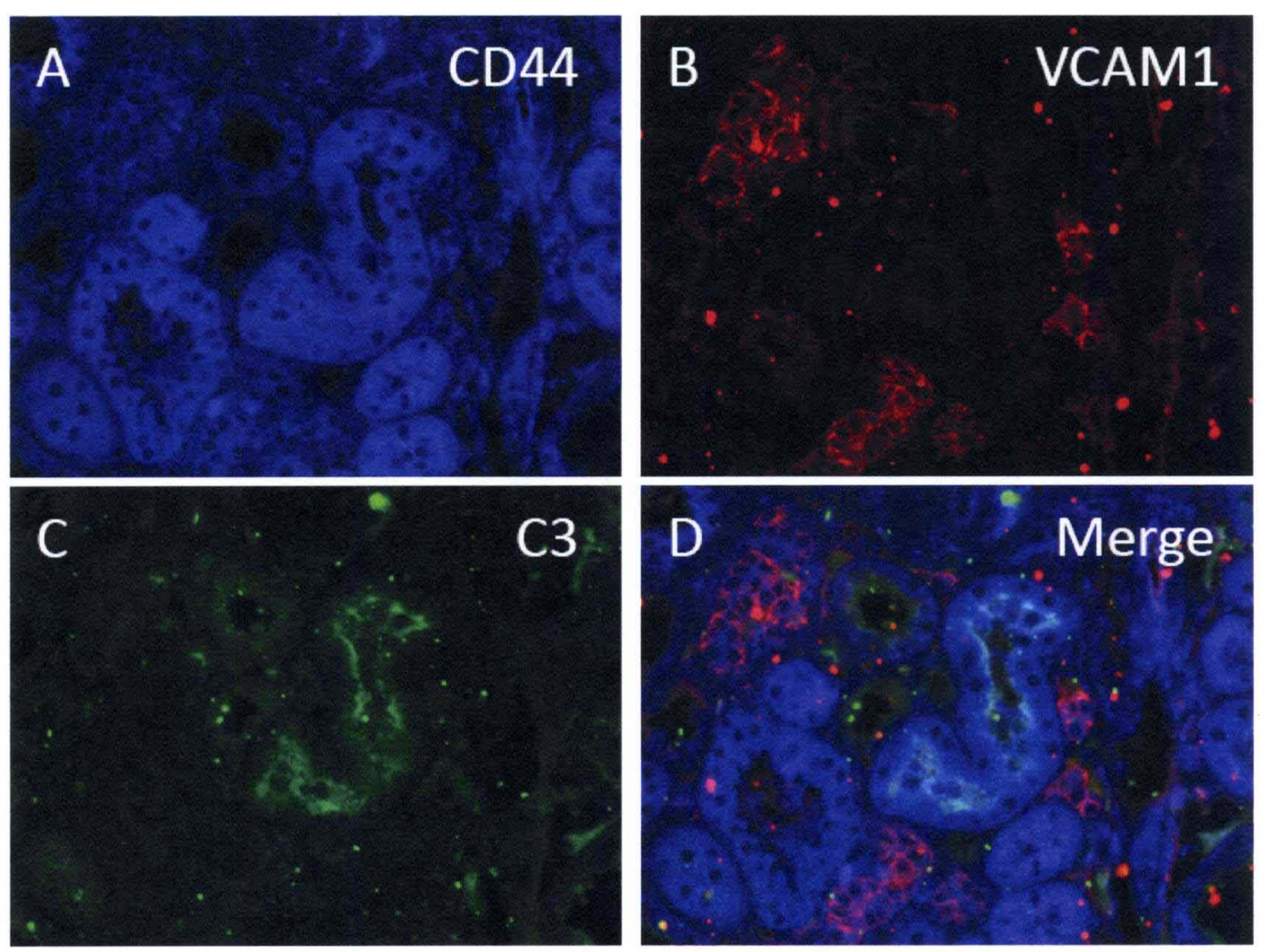


Figure 17. CD44 and VCAM1 are induced in different OVE26 tubules. Kidney

sections from 8 month old OVE26 mice were stained for the indicated antigens in panels A-C and the merged image is shown in panel D. Original magnification X400. 

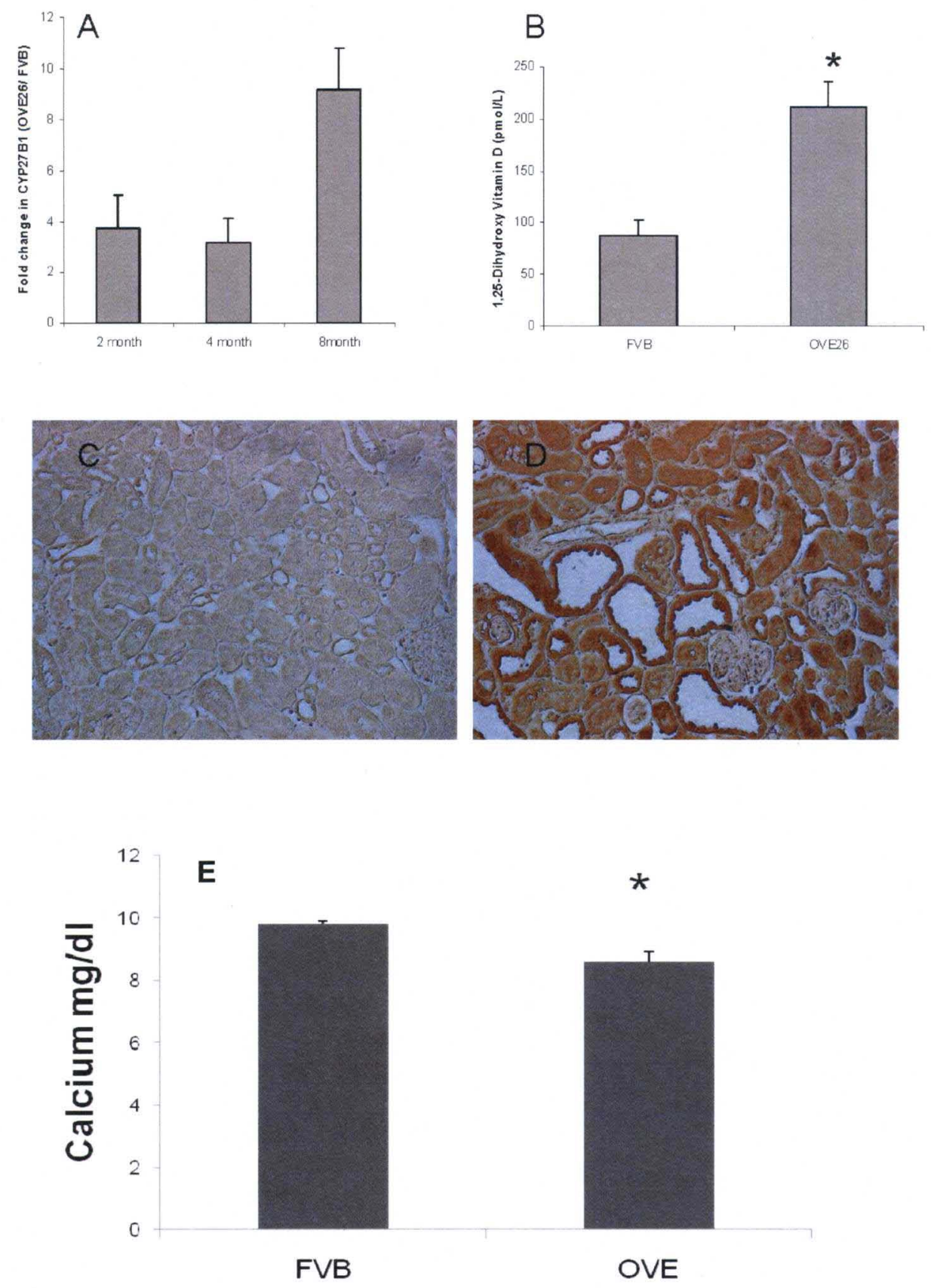
Figure 18. Increased CYP27B1 expression in diabetic mouse kidney and increased serum level of 1,25-dihydroxy vitamin D in diabetic mouse. A) CYP27Bl mRNA is increased in diabetic mouse kidney at all ages based on Affymetrix array results. Y axis indicates the fold change of OVE26 over FVB ( $\mathrm{P} \leq 0.01$ at each age by $t$-test). B) Serum 1,25-dihydroxy vitamin $\mathrm{D}$ levels are elevated $(\mathrm{P}<0.005)$ in 8 month old diabetic mice. Immunohistochemical staining of CYP27B1 on paraffin sections of C) control and D) diabetic kidney. Original magnification X200. E) Serum calcium level is slightly increased in diabetic mice. $(\mathrm{P}<0.01, \mathrm{n}=5)$ 


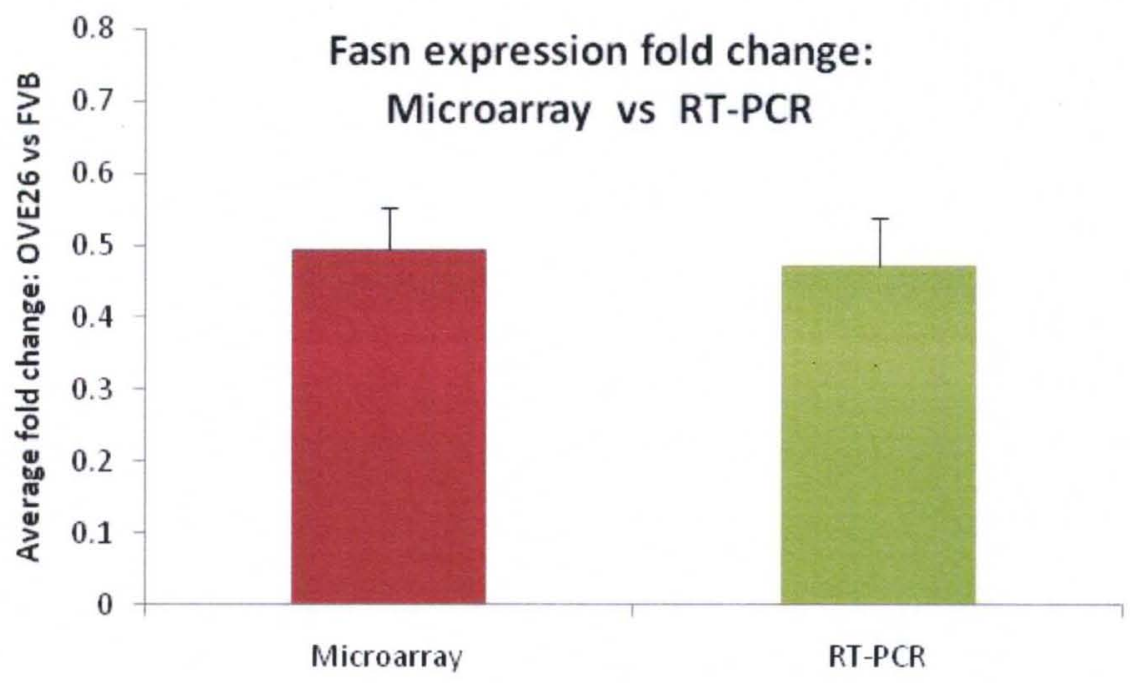


Figure 19. Fasn microarray results were validated by rtPCR using average fold change (OVE26 over FVB). Red column represents microarray results and green column represents rtPCR results. Comparison were made between OVE26 mice and FVB mice. 


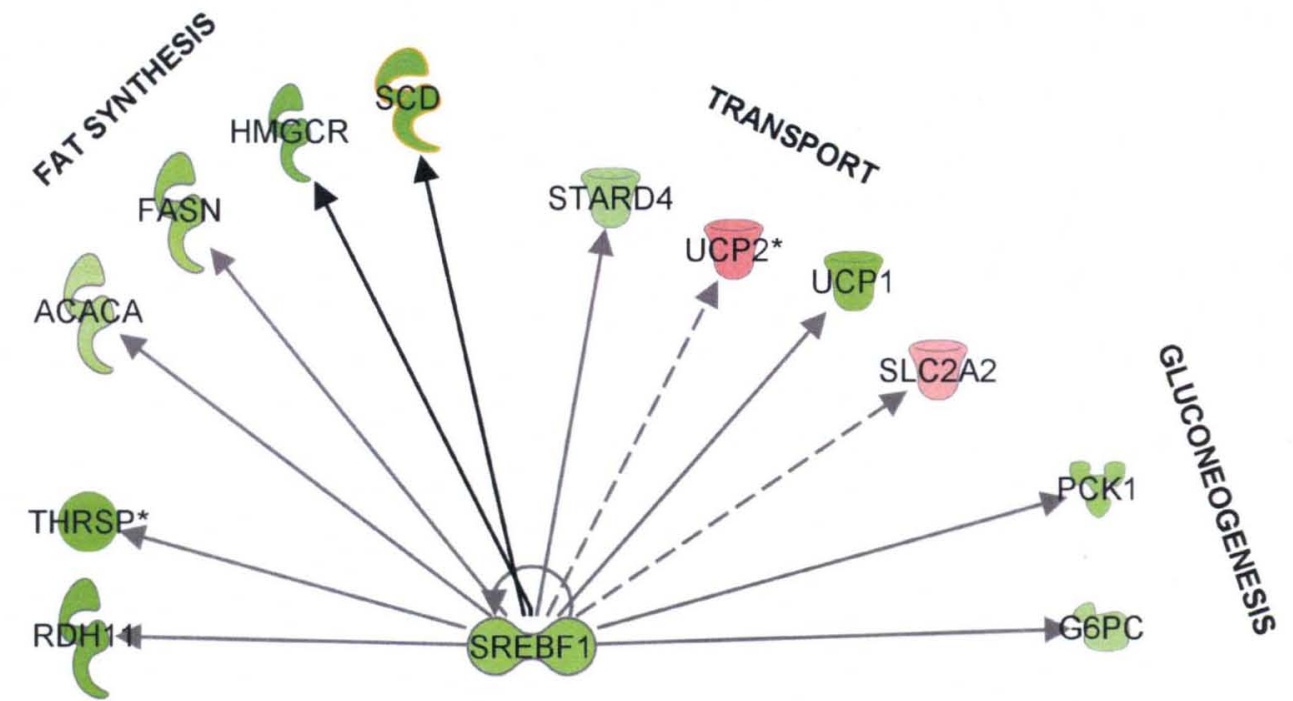

(c) 2000-2010 Ingenuity Systems, Inc. All rights reserved 
Figure 20. SREBF1 regulated genes with significantly altered gene expression in OVE26 kidney. Green symbols and solid arrows indicate that expression was down-regulated in OVE26 mice and that SREBF 1 normally stimulates expression of that gene. Red symbols and dashed arrows indicate that expression was up-regulated in OVE26 mice and that SREBF1 normally inhibits expression of that gene. 


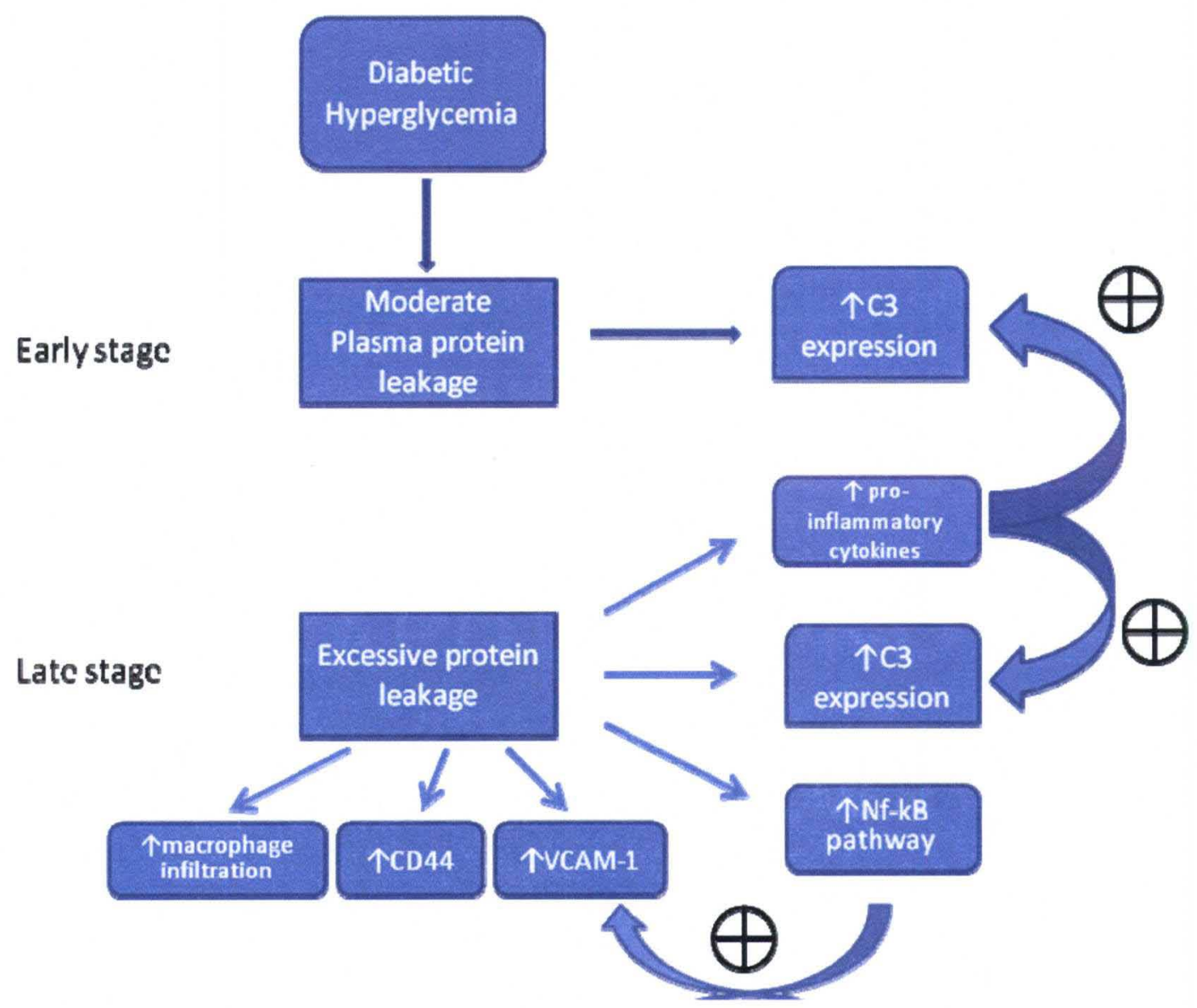


Figure 21. Increased inflammatory genes expression at different stage of diabetes in OVE26 mice. At early stage of diabetes, hyperglycemia can induce moderate protein leakage, which may stimulate $\mathrm{C} 3$ expression. As the disease progressed, C3 expression was further increased possibly regulated by elevated pro-inflammatory cytokines expression. At late stage of diabetes, inflammatory genes CD44 and VCAM1 were up-regulated, which were associated with excessive protein leakage. The severe protein leakage may also promote macrophage infiltration and activate $\mathrm{Nf}-\mathrm{kB}$ transcriptional pathway. The latter may contribute to elevated VCAM-1 expression in the tubules. 


\section{REFERENCES}

United States Renal Data System. USRDS 2007 Annual Data Report. Bethesda, MD: National Institute of Diabetes and Digestive and Kidney Diseases, National Institutes of Health, U.S. Department of Health and Human Services; 2007

1. Muller I, Niethammer D, Bruchelt G (1998) Anthracycline-derived chemotherapeutics in apoptosis and free radical cytotoxicity (Review). Int J Mol Med 1: 491-494.

2. Morgan WA, Kaler B, Bach PH (1998) The role of reactive oxygen species in adriamycin and menadione-induced glomerular toxicity. Toxicol Lett 94: 209-215.

3. Wang Y, Wang YP, Tay YC, Harris DC (2000) Progressive adriamycin nephropathy in mice: sequence of histologic and immunohistochemical events. Kidney Int 58 : 1797-1804.

4. Javaid B, Olson JL, Meyer TW (2001) Glomerular injury and tubular loss in adriamycin nephrosis. J Am Soc Nephrol 12: 1391-1400.

5. Qi Z, Fujita H, Jin J, Davis LS, Wang Y, et al. (2005) Characterization of susceptibility of inbred mouse strains to diabetic nephropathy. Diabetes 54: 2628-2637.

6. Bachur NR, Gordon SL, Gee MV (1978) A general mechanism for microsomal activation of quinone anticancer agents to free radicals. Cancer Res 38: 1745-1750.

7. Mimnaugh EG, Trush MA, Gram TE (1986) A possible role for membrane lipid peroxidation in anthracycline nephrotoxicity. Biochem Pharmacol 35: 4327-4335.

8. Kalyanaraman B, Sealy RC, Sinha BK (1984) An electron spin resonance study of the reduction of peroxides by anthracycline semiquinones. Biochim Biophys Acta 799: 270-275.

9. Olson RD, Boerth RC, Gerber JG, Nies AS (1981) Mechanism of adriamycin cardiotoxicity: evidence for oxidative stress. Life Sci 29: 1393-1401. 
10. Powell SR, McCay PB (1988) Inhibition of doxorubicin-initiated membrane damage by $\mathrm{N}$-acetylcysteine: possible mediation by a thiol-dependent, cytosolic inhibitor of lipid peroxidation. Toxicol Appl Pharmacol 96: 175-184.

11. Hida H, Coudray C, Calop J, Favier A (1995) Effect of antioxidants on adriamycin-induced microsomal lipid peroxidation. Biol Trace Elem Res 47: 111-116.

12. Bertelli R, Ginevri F, Gusmano R, Ghiggeri GM (1991) Cytotoxic effect of adriamycin and agarose-coupled adriamycin on glomerular epithelial cells: role of free radicals. In Vitro Cell Dev Biol 27A: 799-804.

13. Miner JH, Li C (2000) Defective glomerulogenesis in the absence of laminin alpha5 demonstrates a developmental role for the kidney glomerular basement membrane. Dev Biol 217: 278-289.

14. Natoli TA, Liu J, Eremina V, Hodgens K, Li C, et al. (2002) A mutant form of the Wilms' tumor suppressor gene WT1 observed in Denys-Drash syndrome interferes with glomerular capillary development. J Am Soc Nephrol 13: 2058-2067.

15. Koshikawa M, Mukoyama M, Mori K, Suganami T, Sawai K, et al. (2005) Role of p38 mitogen-activated protein kinase activation in podocyte injury and proteinuria in experimental nephrotic syndrome. $J$ Am Soc Nephrol 16: 2690-2701.

16. Zheng S, Noonan WT, Metreveli NS, Coventry S, Kralik PM, et al. (2004) Development of late-stage diabetic nephropathy in OVE26 diabetic mice. Diabetes 53: 3248-3257.

17. Siu B, Saha J, Smoyer WE, Sullivan KA, Brosius FC, 3rd (2006) Reduction in podocyte density as a pathologic feature in early diabetic nephropathy in rodents: prevention by lipoic acid treatment. BMC Nephrol 7: 6 .

18. Lee VWS, Harris DCH (2010) Adriamycin nephropathy - a model of focal segmental glomerulosclerosis. Nephrology: no-no.

19. Pippin JW, Brinkkoetter PT, Cormack-Aboud FC, Durvasula RV, Hauser PV, et al. (2009) Inducible rodent models of acquired podocyte diseases. Am J Physiol Renal Physiol 296: F213-229. 
20. Venkatesan N, Punithavathi D, Arumugam V (2000) Curcumin prevents adriamycin nephrotoxicity in rats. Br J Pharmacol 129: 231-234.

21. Ryan GB, Karnovsky MJ (1975) An ultrastructural study of the mechanisms of proteinuria in aminonucleoside nephrosis. Kidney Int 8: 219-232.

22. Zou MS, Yu J, Nie GM, He WS, Luo LM, et al. (2010) 1, 25-dihydroxyvitamin D3 decreases adriamycin-induced podocyte apoptosis and loss. Int J Med Sci 7: 290-299.

23. Guo J, Ananthakrishnan R, Qu W, Lu Y, Reiniger N, et al. (2008) RAGE mediates podocyte injury in adriamycin-induced glomerulosclerosis. J Am Soc Nephrol 19: 961-972.

24. Kagi JH, Schaffer A (1988) Biochemistry of metallothionein. Biochemistry 27: 8509-8515.

25. Sato M, Bremner I (1993) Oxygen free radicals and metallothionein. Free Radic Biol Med 14: 325-337.

26. Schwarz MA, Lazo JS, Yalowich JC, Reynolds I, Kagan VE, et al. (1994) Cytoplasmic metallothionein overexpression protects NIH 3T3 cells from tert-butyl hydroperoxide toxicity. J Biol Chem 269: 15238-15243.

27. Schwarz MA, Lazo JS, Yalowich JC, Allen WP, Whitmore M, et al. (1995) Metallothionein protects against the cytotoxic and DNA-damaging effects of nitric oxide. Proc Natl Acad Sci U S A 92: 4452-4456.

28. Tamai KT, Gralla EB, Ellerby LM, Valentine JS, Thiele DJ (1993) Yeast and mammalian metallothioneins functionally substitute for yeast copper-zinc superoxide dismutase. Proc Natl Acad Sci U S A 90: 8013-8017.

29. Chen H, Carlson EC, Pellet L, Moritz JT, Epstein PN (2001) Overexpression of metallothionein in pancreatic beta-cells reduces streptozotocin-induced DNA damage and diabetes. Diabetes 50: 2040-2046.

30. Li X, Chen H, Epstein PN (2004) Metallothionein protects islets from hypoxia and extends islet graft survival by scavenging most kinds of reactive oxygen species. J Biol Chem 279: 765-771. 
31. Sun X, Zhou Z, Kang YJ (2001) Attenuation of doxorubicin chronic toxicity in metallothionein-overexpressing transgenic mouse heart. Cancer Res 61: $3382-3387$.

32. Lazo JS, Kuo SM, Woo ES, Pitt BR (1998) The protein thiol metallothionein as an antioxidant and protectant against antineoplastic drugs. Chem Biol Interact 111-112: 255-262.

33. Zheng H, Liu J, Choo KH, Michalska AE, Klaassen CD (1996) Metallothionein-I and -II knock-out mice are sensitive to cadmium-induced liver mRNA expression of c-jun and p53. Toxicol Appl Pharmacol 136: 229-235.

34. Quesada AR, Byrnes RW, Krezoski SO, Petering DH (1996) Direct reaction of $\mathrm{H} 2 \mathrm{O} 2$ with sulfhydryl groups in HL-60 cells: zinc-metallothionein and other sites. Arch Biochem Biophys 334: 241-250.

35. Viarengo A, Burlando B, Ceratto N, Panfoli I (2000) Antioxidant role of metallothioneins: a comparative overview. Cell Mol Biol (Noisy-le-grand) 46: 407-417.

36. Thomas JP, Bachowski GJ, Girotti AW (1986) Inhibition of cell membrane lipid peroxidation by cadmium- and zinc-metallothioneins. Biochim Biophys Acta 884: 448-461.

37. Zhou Z, Sun X, Lambert JC, Saari JT, Kang YJ (2002) Metallothionein-independent zinc protection from alcoholic liver injury. Am J Pathol 160: 2267-2274.

38. Ochi T, Otsuka F, Takahashi K, Ohsawa M (1988) Glutathione and metallothioneins as cellular defense against cadmium toxicity in cultured Chinese hamster cells. Chem Biol Interact 65: 1-14.

39. Ferreira AM, Ciriolo MR, Marcocci L, Rotilio G (1993) Copper(I) transfer into metallothionein mediated by glutathione. Biochem J 292 ( Pt 3): 673-676.

40. Zheng S, Carlson EC, Yang L, Kralik PM, Huang Y, et al. (2008) Podocyte-specific overexpression of the antioxidant metallothionein reduces diabetic nephropathy. $\mathrm{J}$ Am Soc Nephrol 19: 2077-2085.

41. Ye G, Metreveli NS, Ren J, Epstein PN (2003) Metallothionein prevents diabetes-induced deficits in cardiomyocytes by inhibiting reactive oxygen species production. Diabetes 52: 777-783. 
42. Kang YJ, Chen Y, Yu A, Voss-McCowan M, Epstein PN (1997) Overexpression of metallothionein in the heart of transgenic mice suppresses doxorubicin cardiotoxicity. J Clin Invest 100: 1501-1506.

43. Takemoto M, Asker N, Gerhardt H, Lundkvist A, Johansson BR, et al. (2002) A new method for large scale isolation of kidney glomeruli from mice. Am J Pathol 161: 799-805.

44. Hartner A, Eifert T, Haas CS, Tuysuz C, Hilgers KF, et al. (2004) Characterization of the renal phenotype in a mouse model of Marfan syndrome. Virchows Arch 445: 382-388.

45. Sanden SK, Wiggins JE, Goyal M, Riggs LK, Wiggins RC (2003) Evaluation of a thick and thin section method for estimation of podocyte number, glomerular volume, and glomerular volume per podocyte in rat kidney with Wilms' tumor-1 protein used as a podocyte nuclear marker. J Am Soc Nephrol 14: 2484-2493.

46. Huot J, Houle F, Spitz DR, Landry J (1996) HSP27 phosphorylation-mediated resistance against actin fragmentation and cell death induced by oxidative stress. Cancer Res 56: 273-279.

47. Apostolova MD, Chen S, Chakrabarti S, Cherian MG (2001) High-glucose-induced metallothionein expression in endothelial cells: an endothelin-mediated mechanism. Am J Physiol Cell Physiol 281: C899-907.

48. Mitu GM, Wang S, Hirschberg R (2007) BMP7 is a podocyte survival factor and rescues podocytes from diabetic injury. Am J Physiol Renal Physiol 293: F1641-1648.

49. Liu LL, Li QX, Xia L, Li J, Shao L (2007) Differential effects of dihydropyridine calcium antagonists on doxorubicin-induced nephrotoxicity in rats. Toxicology 231: 81-90.

50. Vielhauer V, Berning E, Eis V, Kretzler M, Segerer S, et al. (2004) CCR1 blockade reduces interstitial inflammation and fibrosis in mice with glomerulosclerosis and nephrotic syndrome. Kidney Int 66: 2264-2278.

51. Miller B, Patel VA, Sorokin A (2006) Cyclooxygenase-2 rescues rat mesangial cells from apoptosis induced by adriamycin via upregulation of multidrug resistance protein 1 (P-glycoprotein). J Am Soc Nephrol 17: 977-985. 
52. Li X, Yuan H, Zhang X (2003) Adriamycin increases podocyte permeability: evidence and molecular mechanism. Chin Med J (Engl) 116: 1831-1835.

53. Palmiter RD (2004) Protection against zinc toxicity by metallothionein and zinc transporter 1. Proc Natl Acad Sci U S A 101: 4918-4923.

54. Wharram BL, Goyal M, Wiggins JE, Sanden SK, Hussain S, et al. (2005) Podocyte depletion causes glomerulosclerosis: diphtheria toxin-induced podocyte depletion in rats expressing human diphtheria toxin receptor transgene. J Am Soc Nephrol 16: $2941-2952$.

55. Morioka Y, Koike H, Ikezumi Y, Ito Y, Oyanagi A, et al. (2001) Podocyte injuries exacerbate mesangial proliferative glomerulonephritis. Kidney Int 60: 2192-2204.

56. Teutsch S, Newman J, Eggers P (1989) The problem of diabetic renal failure in the United States: an overview. Am J Kidney Dis 13: 11-13.

57. Breyer MD (2008) Stacking the deck for drug discovery in diabetic nephropathy: in search of an animal model. J Am Soc Nephrol 19: 1623-1624.

58. Fornoni A, Ijaz A, Tejada $T$, Lenz $O$ (2008) Role of inflammation in diabetic nephropathy. Curr Diabetes Rev 4: 10-17.

59. Sahakyan K, Klein BE, Lee KE, Tsai MY, Klein R (2010) Inflammatory and endothelial dysfunction markers and proteinuria in persons with type 1 diabetes mellitus. Eur J Endocrinol 162: 1101-1105.

60. Persson F, Rossing P, Hovind P, Stehouwer CD, Schalkwijk CG, et al. (2008) Endothelial dysfunction and inflammation predict development of diabetic nephropathy in the Irbesartan in Patients with Type 2 Diabetes and Microalbuminuria (IRMA 2) study. Scand J Clin Lab Invest 68: 731-738.

61. Chow FY, Nikolic-Paterson DJ, Ozols E, Atkins RC, Tesch GH (2005) Intercellular adhesion molecule-1 deficiency is protective against nephropathy in type 2 diabetic db/db mice. J Am Soc Nephrol 16: 1711-1722.

62. Provvedini DM, Tsoukas CD, Deftos LJ, Manolagas SC (1983) 1,25-dihydroxyvitamin D3 receptors in human leukocytes. Science 221: 1181-1183. 
63. Veldman CM, Cantorna MT, DeLuca HF (2000) Expression of 1,25-dihydroxyvitamin $D(3)$ receptor in the immune system. Arch Biochem Biophys 374: 334-338.

64. Imazeki I, Matsuzaki J, Tsuji K, Nishimura T (2006) Immunomodulating effect of vitamin D3 derivatives on type-1 cellular immunity. Biomed Res 27: 1-9.

65. van Etten E, Mathieu C (2005) Immunoregulation by 1,25-dihydroxyvitamin D3: basic concepts. J Steroid Biochem Mol Biol 97: 93-101.

66. Segerer S, Nelson PJ, Schlondorff D (2000) Chemokines, chemokine receptors, and renal disease: from basic science to pathophysiologic and therapeutic studies. $\mathrm{J}$ Am Soc Nephrol 11: 152-176.

67. Lo WK (2006) Serum parameters, inflammation, renal function and patient outcome. Contrib Nephrol 150: 152-155.

68. Tan X, Wen X, Liu Y (2008) Paricalcitol inhibits renal inflammation by promoting vitamin D receptor-mediated sequestration of NF-kappaB signaling. J Am Soc Nephrol 19: 1741-1752.

69. Zehnder D, Quinkler M, Eardley KS, Bland R, Lepenies J, et al. (2008) Reduction of the vitamin $\mathrm{D}$ hormonal system in kidney disease is associated with increased renal inflammation. Kidney Int 74: 1343-1353.

70. Teng M, Wolf M, Lowrie E, Ofsthun N, Lazarus JM, et al. (2003) Survival of patients undergoing hemodialysis with paricalcitol or calcitriol therapy. N Engl J Med 349: 446-456.

71. Agarwal R, Acharya M, Tian J, Hippensteel RL, Melnick JZ, et al. (2005) Antiproteinuric effect of oral paricalcitol in chronic kidney disease. Kidney Int 68: 2823-2828.

72. Teng M, Wolf M, Ofsthun MN, Lazarus JM, Hernan MA, et al. (2005) Activated injectable vitamin $\mathrm{D}$ and hemodialysis survival: a historical cohort study. $\mathrm{J}$ Am Soc Nephrol 16: 1115-1125.

73. Wang Y, Zhou J, Minto AW, Hack BK, Alexander JJ, et al. (2006) Altered vitamin D metabolism in type II diabetic mouse glomeruli may provide protection from diabetic nephropathy. Kidney Int 70: 882-891. 
74. Epstein PN, Overbeek PA, Means AR (1989) Calmodulin-induced early-onset diabetes in transgenic mice. Cell 58: 1067-1073.

75. Berthier CC, Zhang H, Schin M, Henger A, Nelson RG, et al. (2009) Enhanced expression of Janus kinase-signal transducer and activator of transcription pathway members in human diabetic nephropathy. Diabetes 58: 469-477.

76. Schmid H, Boucherot A, Yasuda Y, Henger A, Brunner B, et al. (2006) Modular activation of nuclear factor-kappaB transcriptional programs in human diabetic nephropathy. Diabetes 55: 2993-3003.

77. Taylor J, Tibshirani R, Efron B (2005) The 'miss rate' for the analysis of gene expression data. Biostatistics 6: 111-117.

78. Schaeren-Wiemers N, Gerfin-Moser A (1993) A single protocol to detect transcripts of various types and expression levels in neural tissue and cultured cells: in situ hybridization using digoxigenin-labelled cRNA probes. Histochemistry 100: 431-440.

79. Cuff CA, Kothapalli D, Azonobi I, Chun S, Zhang Y, et al. (2001) The adhesion receptor CD44 promotes atherosclerosis by mediating inflammatory cell recruitment and vascular cell activation. J Clin Invest 108: 1031-1040.

80. Zehnder D, Bland R, Walker EA, Bradwell AR, Howie AJ, et al. (1999) Expression of 25-hydroxyvitamin D3-1alpha-hydroxylase in the human kidney. J Am Soc Nephrol 10: 2465-2473.

81. Proctor G, Jiang T, Iwahashi M, Wang Z, Li J, et al. (2006) Regulation of renal fatty acid and cholesterol metabolism, inflammation, and fibrosis in Akita and OVE26 mice with type 1 diabetes. Diabetes 55: 2502-2509.

82. Liang G, Yang J, Horton JD, Hammer RE, Goldstein JL, et al. (2002) Diminished hepatic response to fasting/refeeding and liver $\mathrm{X}$ receptor agonists in mice with selective deficiency of sterol regulatory element-binding protein-1c. J Biol Chem 277: 9520-9528.

83. Horton JD, Shah NA, Warrington JA, Anderson NN, Park SW, et al. (2003) Combined analysis of oligonucleotide microarray data from transgenic and knockout mice identifies direct SREBP target genes. Proc Natl Acad Sci U S A 100: 12027-12032. 
84. Cohen CD, Lindenmeyer MT, Eichinger F, Hahn A, Seifert M, et al. (2008) Improved elucidation of biological processes linked to diabetic nephropathy by single probe-based microarray data analysis. PLoS One 3: e2937.

85. Usui HK, Shikata K, Sasaki M, Okada S, Matsuda M, et al. (2007) Macrophage scavenger receptor-a-deficient mice are resistant against diabetic nephropathy through amelioration of microinflammation. Diabetes 56: 363-372.

86. Susztak K, Bottinger E, Novetsky A, Liang D, Zhu Y, et al. (2004) Molecular profiling of diabetic mouse kidney reveals novel genes linked to glomerular disease. Diabetes 53: 784-794.

87. Zhao HJ, Wang S, Cheng H, Zhang MZ, Takahashi T, et al. (2006) Endothelial nitric oxide synthase deficiency produces accelerated nephropathy in diabetic mice. $\mathrm{J}$ AmSocNephrol 17: 2664-2669.

88. Xu J, Huang Y, Li F, Zheng S, Epstein PN (2010) The FVB Mouse Genotype Confers Susceptibility to OVE26 Diabetic Albuminuria. Am J Physiol Renal Physiol.

89. Abbate M, Zoja C, Remuzzi G (2006) How does proteinuria cause progressive renal damage? J AmSocNephrol 17: 2974-2984.

90. Tang S, Sheerin NS, Zhou W, Brown Z, Sacks SH (1999) Apical proteins stimulate complement synthesis by cultured human proximal tubular epithelial cells. J Am Soc Nephrol 10: 69-76.

91. Morita Y, Ikeguchi H, Nakamura J, Hotta N, Yuzawa Y, et al. (2000) Complement activation products in the urine from proteinuric patients. J Am Soc Nephrol 11: 700-707.

92. Sacks S, Zhou W (2008) New boundaries for complement in renal disease. J Am Soc Nephrol 19: 1865-1869.

93. Tang Z, Lu B, Hatch E, Sacks SH, Sheerin NS (2009) C3a mediates epithelial-to-mesenchymal transition in proteinuric nephropathy. J Am Soc Nephrol 20: 593-603.

94. Quigg RJ, He C, Lim A, Berthiaume D, Alexander JJ, et al. (1998) Transgenic mice overexpressing the complement inhibitor crry as a soluble protein are protected from antibody-induced glomerular injury. J Exp Med 188: 1321-1331. 
95. Tu Z, Kelley VR, Collins T, Lee FS (2001) I kappa B kinase is critical for TNF-alpha-induced VCAM1 gene expression in renal tubular epithelial cells. J Immunol 166: 6839-6846.

96. Rouschop KM, Roelofs JJ, Claessen N, da Costa Martins P, Zwaginga JJ, et al. (2005) Protection against renal ischemia reperfusion injury by CD44 disruption. J Am Soc Nephrol 16: 2034-2043.

97. Sibalic V, Fan X, Loffing J, Wuthrich RP (1997) Upregulated renal tubular CD44, hyaluronan, and osteopontin in kdkd mice with interstitial nephritis. Nephrol Dial Transplant 12: 1344-1353.

98. Rouschop KM, Sewnath ME, Claessen N, Roelofs JJ, Hoedemaeker I, et al. (2004) CD44 deficiency increases tubular damage but reduces renal fibrosis in obstructive nephropathy. J Am Soc Nephrol 15: 674-686.

99. Jones SG, Ito T, Phillips AO (2003) Regulation of proximal tubular epithelial cell CD44-mediated binding and internalisation of hyaluronan. Int $\mathrm{J}$ Biochem Cell Biol 35: 1361-1377.

100. Kralik PM, Long, Y. Song, Y., Yang, L. Wei, H., Coventry, S., Zheng, S., Epstein, P.N. (2009) Diabetic Albuminuria is Due to a Small Fraction of Nephrons Distinguished by Albumin Stained Tubules and Glomerular Adhesions. The American journal of Pathology: In Press.

101. Baeke F, Takiishi T, Korf H, Gysemans C, Mathieu C (2010) Vitamin D: modulator of the immune system. Curr Opin Pharmacol.

102. Bland R, Walker EA, Hughes SV, Stewart PM, Hewison M (1999) Constitutive expression of 25-hydroxyvitamin D3-1alpha-hydroxylase in a transformed human proximal tubule cell line: evidence for direct regulation of vitamin D metabolism by calcium. Endocrinology 140: 2027-2034.

103. Chen YC, Meier RK, Zheng S, Khundmiri SJ, Tseng MT, et al. (2009) Steroidogenic Acute Regulatory (StAR)-Related Lipid Transfer Domain Protein 5 (STARD5) Localization and Regulation in Renal Tubules. Am J Physiol Renal Physiol.

104. Reiniger N, Lau K, McCalla D, Eby B, Cheng B, et al. (2010) Deletion of the receptor for advanced glycation end products reduces glomerulosclerosis and preserves renal function in the diabetic OVE26 mouse. Diabetes 59: 2043-2054. 


\section{CURRICULUM VITAE}

\section{Lu Yang}

\section{Education and Training:}

2010

Ph.D. , Pharmacology and Toxicology, University of Louisville, School of Medicine, Department of Pharmacology \& Toxicology, Louisville, KY

2007 M.S., Pharmacology and Toxicology, University of Louisville, School of Medicine, Department of Pharmacology \& Toxicology, Louisville, KY

2004 B.S., Biophysics \& Neurobiology, University of Science and Technology of China, Department of Neurobiology \& Biophysics, Hefei, China

\section{Awards, Honors:}

2004-2010 University Scholarship \& Fellowship, University of Louisville

1999 Outstanding Student's Scholarship of University of Science \& Technology of

China

\section{Research Experience:}

2002-2004 Research Assistant, Vision Research Laboratory, University of Science and

Technology of China, Department of Neurobiology \& Biophysics

Thesis Title: 
"Expression of $\mu$ opioid receptor in the primary visual pathway and influence of chronic morphine addiction on its expression in visual cortex of cat" Supervisor: Dr. Yifeng Zhou

2004-2010 Graduate Research Assistant, University of Louisville, School of Medicine, Department of Pharmacology \& Toxicology

Supervisor: Dr, Paul N. Epstein

Thesis Title:

"Adriamycin nephrotoxicity is reduced by metallothionein over-expression and kidney gene expression is modified by diabetes in the OVE26 diabetic model"

\section{Peer reviewed Publications:}

1. Yang $L$, Zheng S, Epstein PN. Metallothionein over-expression in podocytes reduces adriamycin nephrotoxicities. Free Radic Res. 2009 Feb;43(2):174-82.

2. Kralik PM, Long Y, Song Y, Yang $\boldsymbol{L}$, Wei H, Coventry S, Zheng S, Epstein PN. Diabetic albuminuria is due to a small fraction of nephrons distinguished by albumin-stained tubules and glomerular adhesions. Am J Pathol. 2009 Aug;175(2):500-9

3. Zheng S, Carlson EC, Yang L, Kralik PM, Huang Y, Epstein PN. Podocyte-specific overexpression of the antioxidant metallothionein reduces diabetic nephropathy. J Am Soc Nephrol. 2008 Nov;19(11):2077-85.

\section{Manuscripts in preparation:}

1. Yang L,Brozovic S, Long YS, Kralik PM, Waigel S, Zacharias W, Zheng S, Epstein PN. Induction of inflammatory gene expression in OVE26 diabetic kidney parallels the onset of severe albuminuria. (submitted)

2. Zheng S, Huang Y, Yang $\boldsymbol{L}$ and Epstein PN. Uninephrectomy of OVE26 mice provides a brief window for observing greatly accelerated diabetic nephropathy.

Selected conference abstracts: 
1. Yang $L$, Brozovic S, Epstein PN. 2008 Progressive Changes in Gene Expression in OVE26 Diabetic Kidney. American Diabetes Association 68th Scientific Sessions. 1103-P.

\section{Professional Societies:}

2008-Present Member, Sigma Xi, The Scientific Research Society 